\title{
PERCEPCIÓN DE LOS TALQUINOS SOBRE SU CALIDAD DE VIDA ${ }^{89}$ RESUMEN
}

El desarrollo humano que ha experimentado nuestra sociedad durante las últimas décadas, acompañado del mejoramiento de las condiciones materiales de vida y de acceso al consumo para una mayoría de los individuos, ha puesto últimamente sobre la mesa la necesidad de discutir sobre los alcances de este bienestar desde la óptica de los propios individuos. Esto ha conllevado a realizar el esfuerzo analítico por entender que el enfoque tradicional de clase social reviste de enormes limitaciones analíticas para lograr aprehender la subjetividad de los individuos en un contexto de sociedades modernas avanzadas. Dado que Talca es un territorio que ha experimentado una acelerada modernización, especialmente después del terremoto del $27 / F$, es que hemos elegido llevar a cabo nuestro estudio en esta ciudad.

\section{PALABRAS CLAVE \\ Desarrollo Humano - Calidad de Vida - Bienestar Subjetivo - Dominios de Vida - Efectos Sociales del Terremoto.}

\section{ABSTRACT}

The human development that has experienced our society during the last decades, accompanied of the improvement of the material conditions of life and of access to the consumption for a majority of the individuals, has put lately on the table the need to discuss the scopes of this well-being from the optics of the own individuals. This has carried to realizing the analytical effort for understanding that the traditional approach of social class re-dresses of enormous analytical limitations to manage to apprehend the subjectivity of the individuals in a context of modern advanced societies. Provided that Talca is a territory that has experienced an intensive modernization, specially after the earthquake of $27 / \mathrm{F}$, it is that we have chosen to carry out our study in this city.

\section{KEY WORDS}

Human Development - Quality of Life - Subjective Wellbeing - Domains of Life Earthquake Social Effects.

\section{INTRODUCCIÓN}

En la actualidad, Chile se presenta como uno de los países latinoamericanos con mayor índice de desarrollo. El Informe de Desarrollo Humano 2013, realizado por el

\footnotetext{
${ }^{89}$ Claudio Vásquez Wiedeman, Sociólogo, Coordinador de la Unidad de Estudios del Centro de Estudios y Gestión Social del Maule, Universidad Autónoma de Chile, sede Talca. Email: cvasquezw@uautonoma.cl
} 
Programa de las Naciones Unidas para el Desarrollo (PNUD) posiciona a nuestro país en el primer lugar en la medición del Índice de Desarrollo Humano (IDH) en América Latina $(0,819$ puntos en un rango de 0 a 1$)$ y en el puesto número $40 \mathrm{a}$ nivel global entre 187 países medidos. Este mismo organismo internacional destaca que " (...) entre 1980 y 2012, la esperanza de vida creció en aproximadamente 10 años; aumentó en más de 3 años la media de escolaridad de adultos, lo mismo que los años esperados de escolaridad, que aumentaron 3,3 años. Del mismo modo, el Ingreso nacional bruto per cápita creció un 175\%. Esto significa que en términos agregados el valor total de IDH de Chile se incrementó en un $28 \%$ en ese período (desde 0,638 en 1980 hasta 0,819 en 2012)" (IDH, 2013).

Pareciera ser entonces que los datos evidencian una realidad indesmentible: Chile se ha desarrollado sosteniblemente generando mejores condiciones materiales de vida para su población. Correlativamente, debiéramos suponer que la calidad de vida de los chilenos también ha mejorado. No obstante, algo pareciera ocurrir que dicha mejora objetiva de las condiciones de vida no se adecua completamente a las expectativas de la ciudadanía, emerge entonces el componente subjetivo del bienestar y del malestar social. La pregunta que nos surgió entonces fue ¿En Talca, el proceso de reconstrucción está generando un acoplamiento entre las expectativas personales y sociales en torno al desarrollo y al mejoramiento de sus condiciones de vida?

Es por este motivo que se diseñó y se realizó esta investigación denominada "percepción de los talquinos sobre su calidad de vida", durante el mes de noviembre del año 2012 recién pasado. El estudio contempló un instrumento cuantitativo de 78 ítems y se administró en terreno a 403 personas, seleccionadas aleatoriamente a través de un procedimiento muestral polietápico, probabilístico en todas sus fases, que comprendió selección de Zonas Censales, Manzanas, Viviendas y finalmente sujetos a partir de un muestreo aleatorio simple. La población encuestada tiene entre 15 años y más y las dimensiones del bienestar subjetivo medidas fueron: SALUD, EMPLEO, INGRESOS, FAMILIA, AMIGOS, COMUNIDAD e INDIVIDUO.

\section{BIENESTAR SUBJETIVO Y CALIDAD DE VIDA}

El desarrollo de las sociedades se evidencia en gran medida a partir del mejoramiento de las condiciones de vida de la población. Esto se traduce en ámbitos tan sensibles como el aumento de la esperanza de vida y la disminución de 
la mortalidad infantil, ampliación de la cobertura de salud, el aumento de los años de escolaridad, el mejoramiento de las condiciones laborales, también de la infraestructura vial, la incorporación de tecnologías en diferentes planos de la vida social, entre muchos otros. No obstante, las mejoras objetivas de las condiciones de vida, para que sean efectivas, deben tener un correlato subjetivo a partir del cual los individuos perciban que sus vidas prosperan de la misma manera que lo hace su entorno. Así entonces, en general, se entiende que el desarrollo está asociado con el mejoramiento de la calidad de vida de las personas.

Por otro lado, los procesos de individualización que ha experimentado la sociedad chilena durante las últimas décadas, ameritan poner la atención en el individuo, tal cual como lo señala Martuccelli: "si el individuo se convierte en objeto principal de reflexión, es, según algunos, porque en adelante los cambios sociales son más visibles a partir de las biografías individuales que de sociografías de grupos o clases sociales". En este sentido es que se relevan las dimensiones de subjetividad / subjetivación e individualidad / individuación como construcciones analíticas que permiten acceder al individuo como foco de análisis sociológico. Al respecto, este autor nos recuerda que la sociología dispone, desde sus orígenes, de tres grandes estrategias intelectuales para el estudio del individuo: la socialización, la subjetivación y la individuación. En la primera de estas, las dimensiones psicológicas están en el centro del análisis; en la subjetivación, la comprensión del individuo para por el estudio de los procesos de dominación existente (la dinámica entre sujeción y emancipación); mientras que en la individuación, en el centro del análisis están los contornos históricos de la condición moderna y su traducción al nivel de las experiencias de los individuos (Martuccelli, 2007). Así, pues entonces, centrar nuestro foco en los individuos reviste introducirnos en dimensiones subjetivas que son construidas por su propia experiencia y que al mismo tiempo están determinadas por aspectos socioculturales que, a su vez, los propios individuos a través de su acción modifican. Desde la óptica del PNUD, la subjetividad es el espacio y el proceso en que los individuos construyen una imagen de sí, de los otros y del mundo en el contexto de sus experiencias sociales (PNUD, 2012). De esta manera, el sujeto está definido socialmente y sus representaciones históricas y culturales del mundo orientan su acción en un contexto social dado, el cual trasciende disposiciones normativas referidas a una determinada "clase social" respondiendo a mecanismos individualizadores basados en la experiencia motivada por su interacción en contextos socioculturales específicos. Esta experiencia subjetiva es lo que lleva a los individuos construir evaluaciones tanto de sí mismos como del entorno social, configurando apreciaciones en diferentes planos de la vida social en los que los individuos se desempeñan.

La conexión que intentamos realizar en este estudio está referida al hecho de vincular aquellos aspectos subjetivos propios de los individuos relativos a su 
bienestar. Como señalamos en un comienzo, el interés sociológico de esta investigación está en analizar el fenómeno del desarrollo, entendiéndolo como un proceso material (económico, político, territorial, etc.) e inmaterial (cultural, sinergético) cuyo fin es el mejoramiento de las condiciones de vida de los individuos en un sentido factual externalizable y por tanto objetivable, pero también en un sentido subjetivable a partir de la percepción de bienestar subjetivo de los propios individuos. Tanto la dimensión objetiva como la subjetiva del bienestar se entienden como componentes de la calidad de vida. De acuerdo al Informe de Desarrollo Humano 2012 elaborado por el Programa de Naciones Unidas para el Desarrollo (PNUD, 2012), a su vez, esta dimensión subjetiva del bienestar se escinde en una dimensión individual y en otra social, de la manera que sigue:

\section{Componentes de la Calidad de Vida (IDH, 2012)}

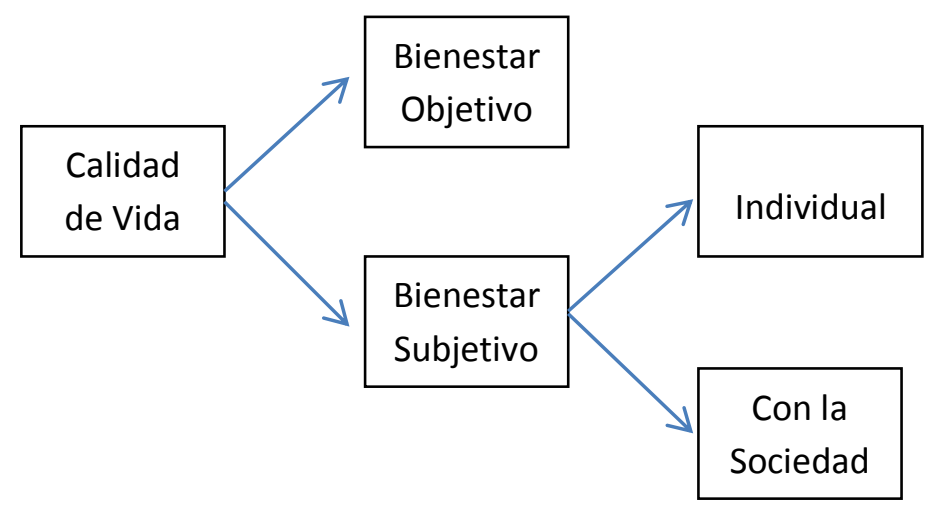

En efecto, entendemos que calidad de vida es un constructo multidimensional que está compuesto, al menos, por una dimensión objetiva y otra subjetiva. La dimensión objetiva o material se operacionaliza a través de la posesión de bienes y el acceso a servicios, mientras que la dimensión subjetiva resulta ser más compleja, pues deviene en percepciones y actitudes que tienen los sujetos en relación con su experiencia vivencial. De esta manera, se entiende que dos sujetos que tienen un nivel de ingresos similar $y$, por lo tanto, acceso a niveles de consumo semejantes, su calidad de vida será valorada de manera diferente si uno de los sujetos cuenta con una red de relaciones familiares y afectivas más densa que el otro, o bien, si el estado de salud de un sujeto es mejor que el del otro. Profundizaremos en el marco teórico esta relación entre Calidad de Vida (Moyano, 2007), Bienestar Subjetivo (PNUD, 2012) y Satisfacción en Dominios de la Vida (Rojas, 2010). Por su parte, el bienestar subjetivo individual alude al estado subjetivo que resulta de la evaluación cognitiva-emocional que realiza el individuo de su vida, mientras que el bienestar subjetivo con la sociedad alude al estado subjetivo que resulta de la evaluación cognitiva-emocional que hace de la sociedad en que vive (PNUD, 2012). La discusión que propone el IDH 2012 remite al hecho de señalar que un objetivo del 
desarrollo debe ser que la sociedad genere las condiciones para que las personas tengan evaluaciones positivas, tanto a nivel de vida individual como también respecto de la sociedad de la que forman parte. De este modo, aun cuando existe un amplio margen asociado con la valoración del grado de satisfacción personal que los sujetos tienen respecto de sus vidas personales en el que la sociedad no puede interceder, aun así la sociedad puede hacer una gran diferencia si construye las condiciones que les permitan a las personas desarrollar en plenitud sus capacidades (PNUD, 2012).

\section{CONTEXTUALIZACIÓN}

Cuando nos hacemos la pregunta acerca del "bienestar" y la "calidad de vida" de los chilenos, necesariamente nos contra preguntamos ¿de qué tipo de chilenos estamos hablando? Al respecto, y para contextualizar la respuesta, este estudio lo desarrollamos en la comuna de Talca, Región del Maule, la cual destaca por ser la quinta región con mayor nivel de pobreza en el país $(16,2 \%)$ y la segunda región con menor "satisfacción con la vida" (6,8 pts.), el 56\% de la población tiene un nivel de escolaridad hasta "educación básica completa" y el 35,5\% de su población habita en sectores rurales, según la CASEN 2011. Según datos del INE, la comuna de Talca tiene 249.993 habitantes, dasagregados por sexo: $51 \%$ de mujeres y $49 \%$ de hombres y según rango de edad: 0 - 14 años (22\%), 15 - 29 años (21\%), 30 44 años $(22 \%), 45-64$ años $(23 \%)$ y 65 años y más (12\%), siendo el ingreso per cápita autónomo promedio $\$ 154.588$.

En términos geográficos, aunque la ciudad de Talca está tan sólo a 270 kilómetros al sur de Santiago, no obstante es la capital regional que, en términos relativos, se encuentra más lejos de la metrópoli entre todas las capitales regionales del país. Esto es así porque, a pesar de que las capitales regionales de las zonas extremas del país, Arica, por el extremo norte, se ubica 2.059 kilómetros y Punta Arenas, por el extremo sur, a 3.004 kilómetros, a Talca se llega sólo por carretera (dado que la región carece de aeropuerto) demorando aproximadamente el viaje 3 horas 15 minutos, mientras que a Arica el avión demora 2 horas 30 minutos sin escalas, a Punta Arenas demora alrededor de 3 horas.

Lo señalado anteriormente, que sólo pudiese parecer un dato de la causa, genera ruido en la Región del Maule por evocar una sensación de aislamiento respecto del centro político, industrial, financiero y cultural de Chile. En un país tan centralizado como el nuestro esto no es menor, pues, a nuestro juicio, los procesos sociohistóricos y socioculturales que configuraron este territorio y sus rasgos identitarios, tienen una raigambre cultural tradicional que está incrustada en el adn del maulino. De esta manera, el auge y esplendor que alguna vez tuvo este territorio y particularmente la ciudad de Talca fue consagrado desde los albores de 
la colonización por el propio gobernador de Chile. Ya en el siglo XVIII Ambrosio O'Higgins alababa las bondades de los terrenos de la zona maulina, generosos para "la crianza de ganados, siembra de trigo y plantaciones de viñas y árboles frutales" (de Ramón, 1995). De manera tal que dichas condiciones propiciaron el pronto crecimiento del territorio. El mismo O'Higgins padre retrataba las generosidades de Talca comparándola incluso con Santiago: "Estimaba en unas cinco mil personas las que componían todo "el vecindario del recinto", las que habitaban una ciudad con calles "largas, derechas y alguna parte de ellas bien empedradas", con "casas cuasi de igual magnificencia que la de esta capital (Santiago)", opulentas y lucidas..." (de Ramón, 1995). Otro dato importante de consignar como antecedente, es que el 20 de Febrero de 1835 aconteció un fuerte terremoto con epicentro en Concepción devastando gran parte de las construcciones de la ciudad de Talca con consecuencias en la población perdurables por muchos años en el tiempo. Así lo retrata un periódico de la época, El Alfa (No 126) de 20 de Marzo de 1847. Según el periodista, a doce años de aquel terremoto, la población de la ciudad de Talca todavía se hallaba diseminada en todas direcciones dentro del espacio de una legua desde la plaza principal y sin que en muchas partes se continuaran las calles, ni hubiera edificios sino que estos se veían dispersos y desordenados indicados que la reconstrucción de la ciudad se estaba haciendo muy lentamente (de Ramón, 1995). Según el historiador, esta lentitud en la reconstrucción no era causada por motivos económicos sino más bien por la tendencia y el apego de sus habitantes a la vida rural. De esta manera, la prosperidad de la ciudad de Talca entrelazaba la expansión demográfica y el desarrollo de algunas industrias relacionadas con la producción de mercancías derivadas del cebo, el cuero y la carne del ganado además de la actividad agropecuaria; "dos fundiciones, diez molinos, dos fábricas de carruajes, tres talabarterías, tres tapicerías, dos mueblerías, dos sombrerías, tres cervecerías, cinco panaderías, etc." (de Ramón, 1995). Todo lo anterior en un contexto de significativa ruralidad del que la elite oligárquica latifundista trataba de diferenciarse a partir del consumo de muebles, telas y artefactos de lujo importados de Europa, principalmente de Francia e Inglaterra, emulando en parte a la aristocracia santiaguina. Con posterioridad, este constitutivo desarrollo basado en las exportaciones agrícolas y demás productos derivados del tratamiento industrial de este sector, se fue debilitando con la progresiva disminución de las exportaciones y del consumo del mercado interno. Como lo señala el profesor Gerardo Sánchez, "el cambio de modelo político en la metrópoli generará cambios profundos en la elite dirigente, quien en su intento de "modernizarse" cae en el consumo y dilapidación, pero con dejos de ruralidad" (Sánchez, 2012). De esta manera, a medida que avanzó el proceso de modernización, incluso durante todo el siglo XX, la estructura social maulina en general y talquina en particular, se constituyó en torno a quienes eran propietarios de la tierra y entre quienes trabajaban para ellos. Entremedio se ubicaba un grupo de comerciantes y de industriales que terminaron por disolverse a partir de la apertura económica del país y la escasa posibilidad de competir frente a 
los productos importados. De esta manera, Sánchez enfatiza como "complejas" las relaciones entre las diferentes clases sociales pues la diferencia entre los mundos conformados por la "oligarquía terrateniente" y la "clase trabajadora" se constituían en torno a la obediencia y sumisión de la segunda respecto de la primera, rasgos culturales perdurables simbólicamente hasta el día de hoy: "el sujeto popular (mestizo) coexistirá en complejas relaciones con los representantes de la aristocracia y luego de la oligarquía, en su intento de ganarse un espacio, proyecto que perdura hasta el presente" (Sánchez, 2012).

\section{DESARROLlO humano Y CALIDAD DE VIDA DESDE EL BIENESTAR SUBJETIVO}

Creemos que el fin último de las sociedades es el desarrollo humano de los individuos, por lo tanto, -bajo el prisma de Norbert Elias- desde nuestra perspectiva, la sociedad es un medio y el individuo es el fin. Y en virtud de este fin de la sociedad, que es el bienestar de los individuos, entendemos que la modernización durante las últimas tres décadas de la sociedad chilena, ha generado un avance sustantivo en materias de cobertura en salud, educación, empleo, infraestructura, ampliación de libertades individuales y principalmente acceso al consumo de bienes y servicios. Chile es presentado como un ejemplo en el mundo, por nuestra forma de desarrollo producto de una economía neoliberal radicalmente abierta al mundo, por tener un estado observador "regulador" que no se mete en asuntos de la economía y por ser un país ordenado, con ciudadanos sumamente respetuosos de sus instituciones. De esta manera, la imagen de Chile es vendida en el orbe como un paraíso neoliberal. No obstante, toda esta buenaventura y prosperidad económica durante los últimos años ha colisionado con un malestar social que ha generado cierto consenso en sectores amplios de la población, especialmente entre aquellos que luchan por relevar en nuestro país una sociedad de ciudadanos y no exclusivamente de consumidores. Para algunas altas autoridades políticas, la educación es un bien de consumo mientras que, por el contrario, para muchos chilenos la educación pública de calidad es un derecho que debe ser garantizado por el Estado y financiado a partir de una reforma tributaria en la que los grandes empresarios nacionales y las empresas multinacionales, paguen mucho más impuesto. Sin lugar a dudas, en estas materias no existe consenso pero se evidencia una tensión entre el discurso de la clase política y el imaginario colectivo de la sociedad en términos de tres grandes ejes: salud, educación y previsión social.

Es así como se entiende que desde el plano del bienestar social, la modernización de la sociedad ha generado notables avances que pueden ser cuantificables, pero 
sin embargo estos avances no necesariamente son percibidos y sintonizados por toda la población. $Y$ es que producto de los mecanismos de segregación del consumo en el mercado, algunos ciudadanos-consumidores gozan ampliamente de las bondades que ofrece la sociedad, mientras que grandes masas quedan excluidas de los beneficios del modelo teniendo que conformarse con la subsistencia. Entremedio del sector privilegiado, conformado por individuos que gozan y disfrutan holgadamente en la sociedad chilena neoliberal y de aquellos sectores marginados, conformados por individuos que dificultosamente subsisten el día a día, se encuentran los amplios sectores de individuos de clases medias que intentan disfrutar de las bondades de la sociedad neoliberal, pero para ello deben endeudarse más allá de sus capacidades reales de generación de ingresos. De esta manera, la multiplicidad de vivencias individuales y grupales que coexisten en nuestra sociedad retrata subjetividades que construyen la realidad social y la apropian a través de diferentes mecanismos, configurando mundos intersubjetivos en los que los individuos se encuentran cotidianamente. Tal como lo señala el Informe de Desarrollo Humano 2012, "La subjetividad es el proceso en que los individuos contruyen una imagen de si, de los otros y del mundo en el contexto de sus experiencias sociales. Su núcleo es el trabajo de constitución de si en el mundo, es decir el trabajo que realiza cada individuo para constituir un si mismo que le permitirá afirmarse y orientarse como un ser individual dotado de valor en el contexto de sus relaciones sociales" (PNUD, 2012). Por lo tanto, entendemos que la subjetividad no nace con el individuo, sino que es el resultado de un proceso de construcción individual y social, a través del cual el individuo va internalizando, desde de su propia experiencia, los significados, símbolos y normas sociales que emergen y estructuran el mundo en el que vive e interactúa. El individuo constituye una imagen de sí a partir del diálogo que entabla consigo mismo en términos principalmente morales, por lo tanto, la imagen de sí es simpre una imagen moral: los individuos realizan juicios de valor sobre sí mismos en función de los referentes que se han apropiado. Por otra parte, la imagen del mundo está influida por un juicio práctico; a partir de su experiencia social concreta, el individuo elabora juicios sobre el mundo, dependiento de sus aspiraciones, necesidades e intereses. La imagen del mundo comporta siempore un juicio crítico: ¿en qué medida el entorno me permite ser lo que quiero o debo ser? (PNUD, 2012). En consecuencia, la multiplicidad de "micromundos sociales" que coexisten dentro de cada sociedad da pie a la emergencia de una gran variedad de interpretaciones subjetivas. Por ejemplo, en nuestra capital una gran cantidad de individuos utiliza el sistema de transporte público todos los días, para los cuales la dificultad de conectividad entre los componentes del sistema de transporte y el déficit de frecuencia de los recorridos es un problema importante. Frente a ello, es lógico suponer que para esa gran cantidad de santiaguinos, este problema en el transporte produce 
malestar. Antagónicamente, en la misma ciudad de Santiago, existen individuos que no utilizan el transporte público ${ }^{90}$ por lo cual para ellos el deficit de conectividad y frecuencia del transporte no es un problema que genere malestar. Estamos hablando de individuos que coexisten en un mismo territorio, pero que sus apreciaciones respecto del mundo socialmente compartido son diferentes. Y así como los individuos emiten juicios y apreciaciones sobre su entorno social, también lo hacen en relación a sí mismos, sus familias, amistades, trabajo, salud, etc.

Es así como hoy en día las Ciencias Sociales entienden que el "estado de ánimo", el "nivel de satisfacción de los individuos" incluso los "niveles de felicidad", son criterios importantes a tomar en consideración al momento de pensar el desarrollo humano. De esta manera, la discusión sobre el bienestar subjetivo se torna cada vez más central cuando se discute sobre desarrollo, puesto que existe un consenso más o menos instalado a nivel global respecto de que el desarrollo, en cuanto meta deseable, no es un fin en sí mismo, sino que sería un medio para alcanzar mayores niveles de bienestar subjetivo como fin último del desarrollo. Esta noción alude a que la sociedad genere las condiciones necesarias para que las personas se sientan satisfechas, tanto con sus vidas como con la sociedad en que despliegan esas vidas (PNUD, 2012).

Pero, si entonces nuestra sociedad experimenta tales niveles de "progreso", ¿por qué entonces se suceden discursos provenientes de amplios sectores sociales y del mundo político extraparlamentario, que reclaman la necesidad de generar cambios estructurales en el sistema social: cambio de modelo socioeconómico, cambio del sistema de representación político, ampliación del rol del estado, renacionalización del cobre y nacionalización de otros recursos naturales, término al sistema de pensiones AFP, entre otras demandas sociales?, ¿por qué si como sociedad nos vamos desarrollando tan bien, existe un amplio consenso en importantes sectores de la sociedad que es necesario cambiar el rumbo?. Siguiendo con el análisis del desarrollo chileno, el Informe de Desarrollo Humano 2012 señala: "Al examinar la situación actual de la subjetividad en Chile el diagnóstico general aparece con claridad: ha aumentado la satisfacción de los chilenos con sus vidas personales $y$ al mismo tiempo, se ha incrementado el malestar de las personas con la sociedad" (PNUD, 2012). Y pareciera ser que los procesos de individualización de nuestra sociedad, que han sido acompañados de crecientes niveles de inseguridad, de temor al otro, de desconfianza en las instituciones (siendo las políticas las peores evaluadas) evidencian precisamente ese malestar

\footnotetext{
${ }^{90} \mathrm{Al}$ respecto es interesante hacer notar el hecho de que existen agrupaciones de ciclistas, tal como el movimiento furiosos ciclistas, que reivindican su derecho a desplazarse en dos ruedas por la ciudad, demandando para ello políticas de construcción de ciclovías para garantizar la seguridad vial, además de motivar a que cada vez más personas se atrevan a subirse a una bicicleta para usarla como su medio de transporte habitual. http://www.furiosos.cl/movimiento-furiosos-ciclistas/
} 
con la sociedad. Para muchos individuos, este sistema no les está permitiendo gozar de las bondades de la modernización de la sociedad sino que, por el contrario, los está aislando, dejando en evidencia la descomposición de los lazos sociales, la desarticulación del tejido social. Luego, nos enfrentamos a un modelo sociocultural en el que los individuos no solo experimentan débiles niveles de confianza hacia las instituciones sino que también hacia otros individuos. Al menos así lo grafica la encuesta CEP Auditoría a la Democracia (Noviembre 2012), a partir de la cual se puede evidenciar que los chilenos tenemos un bajísimo nivel de confianza hacia nuestros compatriotas, pues tan sólo uno de cada cinco individuos piensa que se puede confiar en los otros.

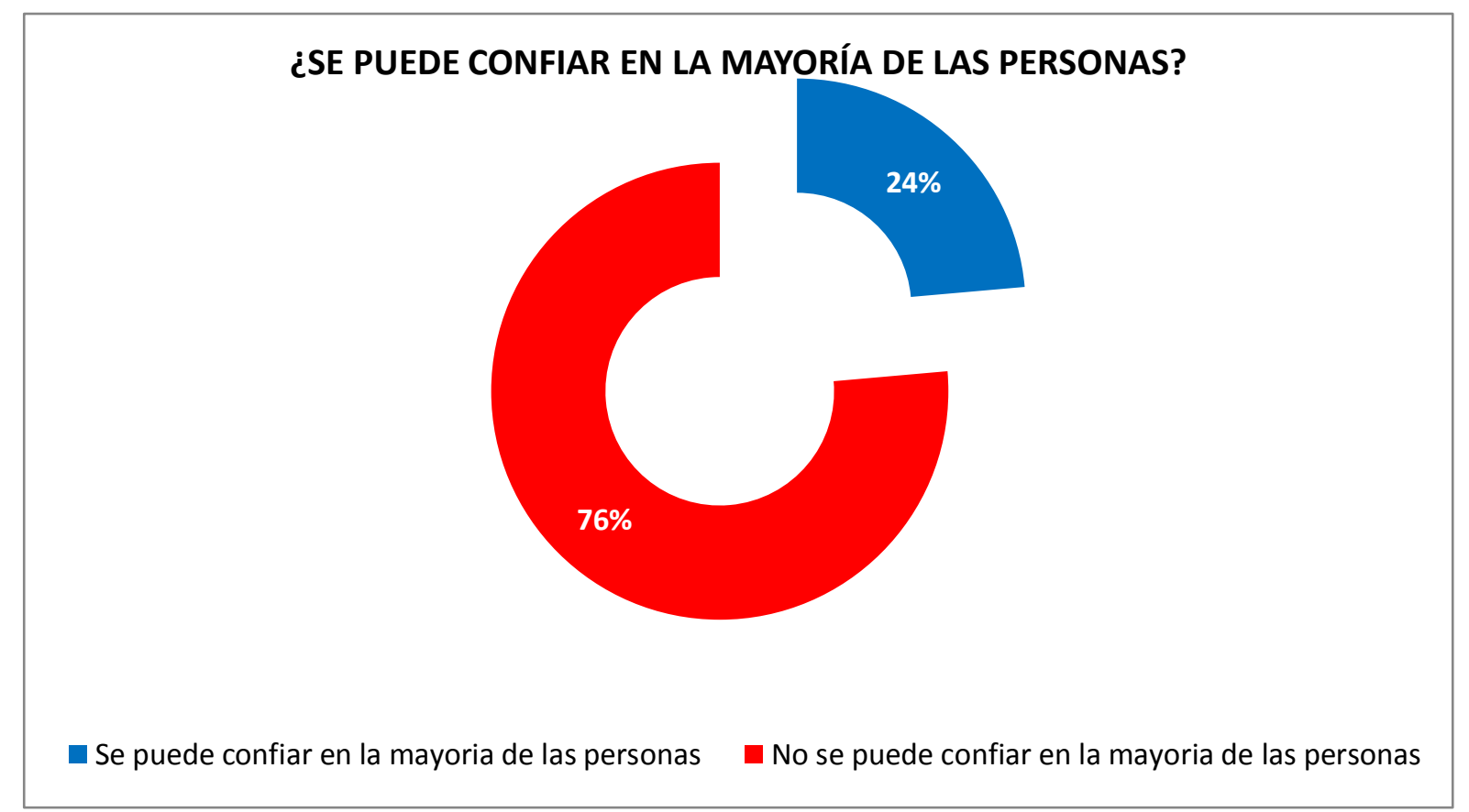

Fuente: Elaboración propia a partir de la base de datos Auditoría a la Democracia 2012, CEP-Chile.

\section{SATISFACCIÓN EN DOMINIOS DE VIDA}

El bienestar subjetivo se compone de una dimensión cognitiva y otra afectiva. La dimensión cognitiva es operacionalizada a partir del enfoque de los dominios de vida y la importancia que le atribuimos a este enfoque es que los propios individuos son quienes mejor conocimiento tienen de sí mismos y de sus propias vidas antes que cualquier intento experto por definir un criterio externo. Como señalan Rojas y 
Elizondo: "este enfoque se preocupa por estudiar y entender el bienestar que las personas experimentan; por ello, puede afirmarse que a diferencia de muchos enfoques académicos, el bienestar subjetivo se preocupa por un bienestar que no es ajeno al sujeto sino que, por el contrario, es un bienestar que las personas experimentan y del cual son conscientes" (Rojas y Elizondo, 2012). De esta manera, según el esquema señalado anteriormente en la figura 6, la Satisfacción Vital y Los Dominios de Vida son parte del componente cognitivo del Bienestar Subjetivo, mientras que la felicidad es parte de su componente afectivo. Pues bien, la Satisfacción Vital y los Dominios de Vida están íntimamente relacionados dado que a partir de la satisfacción experiencial es posible evaluar la situación de las personas en sus diferentes planos de vida. Como señala Mariano Rojas, investigador de FLACSO México: "el enfoque de dominios de vida plantea que la satisfacción de vida es el resultado de la satisfacción personal en cada una de las diferentes facetas o áreas concretas donde se ejerce como ser humano" (Rojas, 2011).

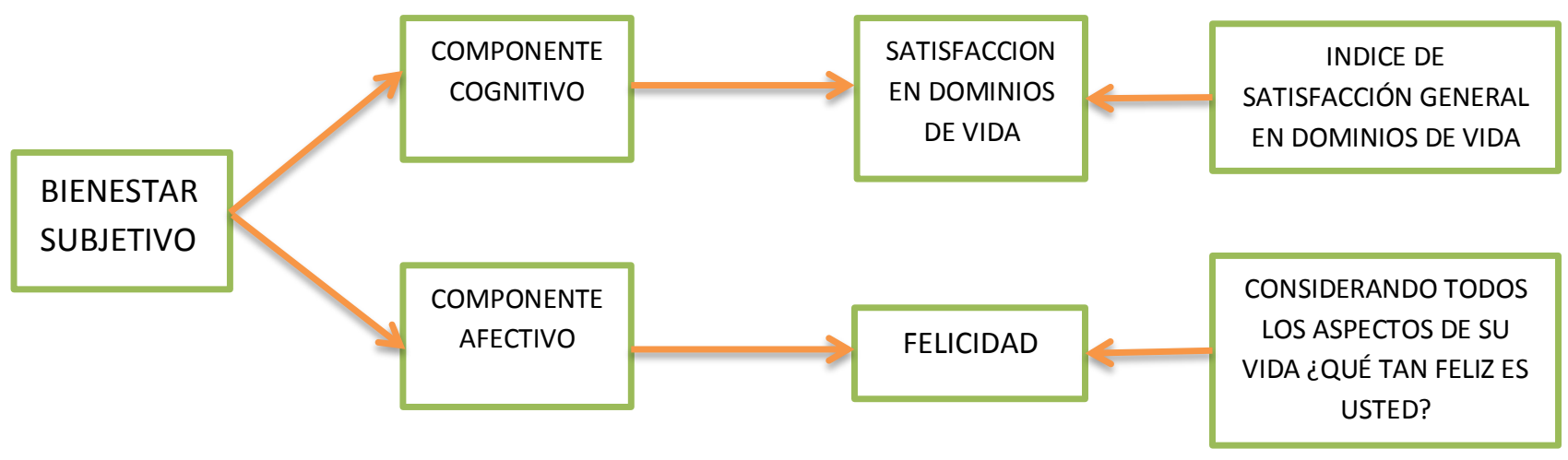

Se entiende, desde esta perspectiva, que existen varias dimensiones o dominios de vida en los que las personas se desenvuelven, no habiendo un consenso absoluto de cuáles serían estos dominios, pero en rigor los podríamos agrupar en 4 áreas: Salud, Afectividad, Situación Económica-Material y Situación Personal. Según el registro sistemático realizado por Rojas y Elizondo, estos dominios de vida se podrían considerar como los siguientes: "con base en un meta-análisis de la literatura, Cummins (1996) define siete dominios de vida; estos son: el bienestar material, la salud, la productividad, la vida privada, la seguridad, la vida en comunidad, y la situación emocional. Por otra parte, van Praag, Frijters y Ferrer-iCarbonell (2003) estudian la relación que existe entre diferentes dominios de vida (salud, situación financiera, empleo, vivienda, ocio y medio ambiente) y la satisfacción de vida" (Rojas y Elizondo, 2012). De esta manera, la medición cuantitativa se realizará en base a la satisfacción de los individuos con sus vidas en los diferentes dominios en los que se cumplen diferentes roles. A continuación, se 
especifican las diferentes dimensiones y su relación empírica con el bienestar, a partir de la documentación realizada por Moyano y Ramos (2007).

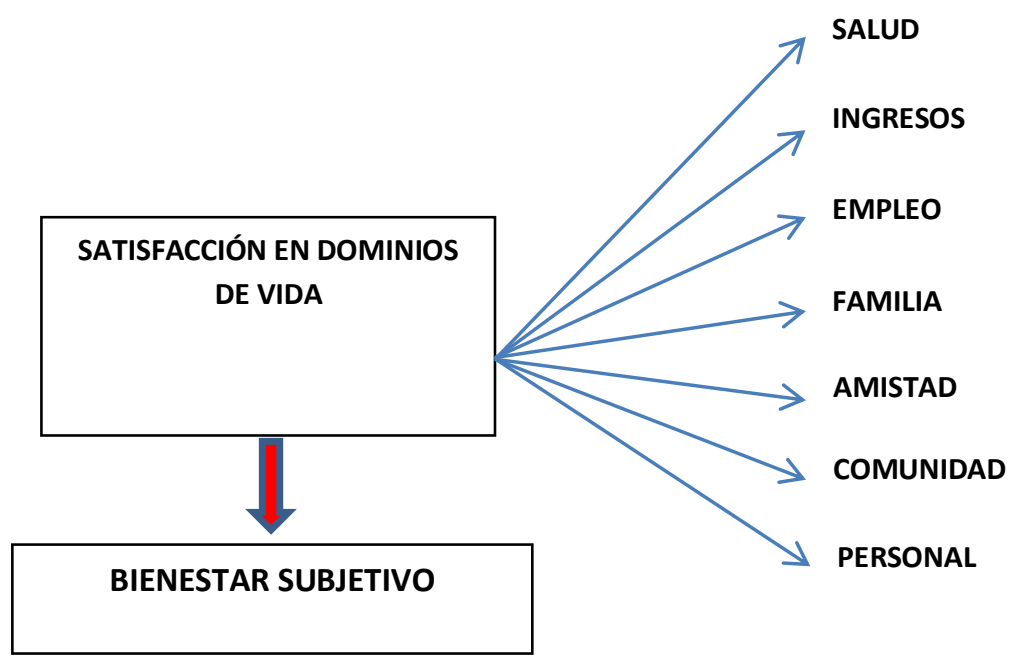

Por lo tanto, la percepción de bienestar subjetivo va a estar influenciada por la satisfacción que experimenten los individuos en los diferentes planos de sus vidas, de manera tal que pretendemos en este documento demostrar el agrupamiento de las variables medidas en torno a estas siete dimensiones o componentes. A continuación, presentamos los análisis realizados en dos partes. La primera se remite a análisis descriptivo para cada una de las siete dimensiones especificadas en esta investigación, mientras que la segunda parte consiste en un análisis de componentes principales de carácter confirmatorio, por cuando nos permitirá conocer el patrón de agrupamiento de las variables consideradas en este estudio en torno a las siete dimensiones señaladas.

\section{PRIMERA PARTE: ANÁLISIS DESCRIPTIVO}

El análisis descriptivo nos permite evidenciar la naturaleza y la magnitud del fenómeno en estudio. Entendiendo que el fenómeno es la calidad de vida de los 
talquinos, la aproximación a esta se realizó a partir del enfoque del bienestar subjetivo, desde el cual se procedieron a operacionalizar y medir las siete dimensiones relacionadas con la satisfacción en los dominios de vida, según el criterio señalado.

\section{MODULO 1: SALUD}

La salud en este estudio la entendemos compuesta por el estado de salud subjetivo del individuo, es decir, como cada cual evalúa su condición de salud y también la percepción que existe en torno al acceso a los servicios médicos en la ciudad. Complementariamente, se evalúa las condiciones materiales de los servicios de salud, la disponibilidad existente de especialidades médicas.

Comenzando por la evaluación objetiva de su salud, los talquinos en general gozan de buena salud, entendiendo que tan solo el $13 \%$ ha sufrido algún tipo de enfermedad durante el mes anterior al estudio y de aquel porcentaje, tan sólo el $4 \%$ requirió ser hospitalizado.

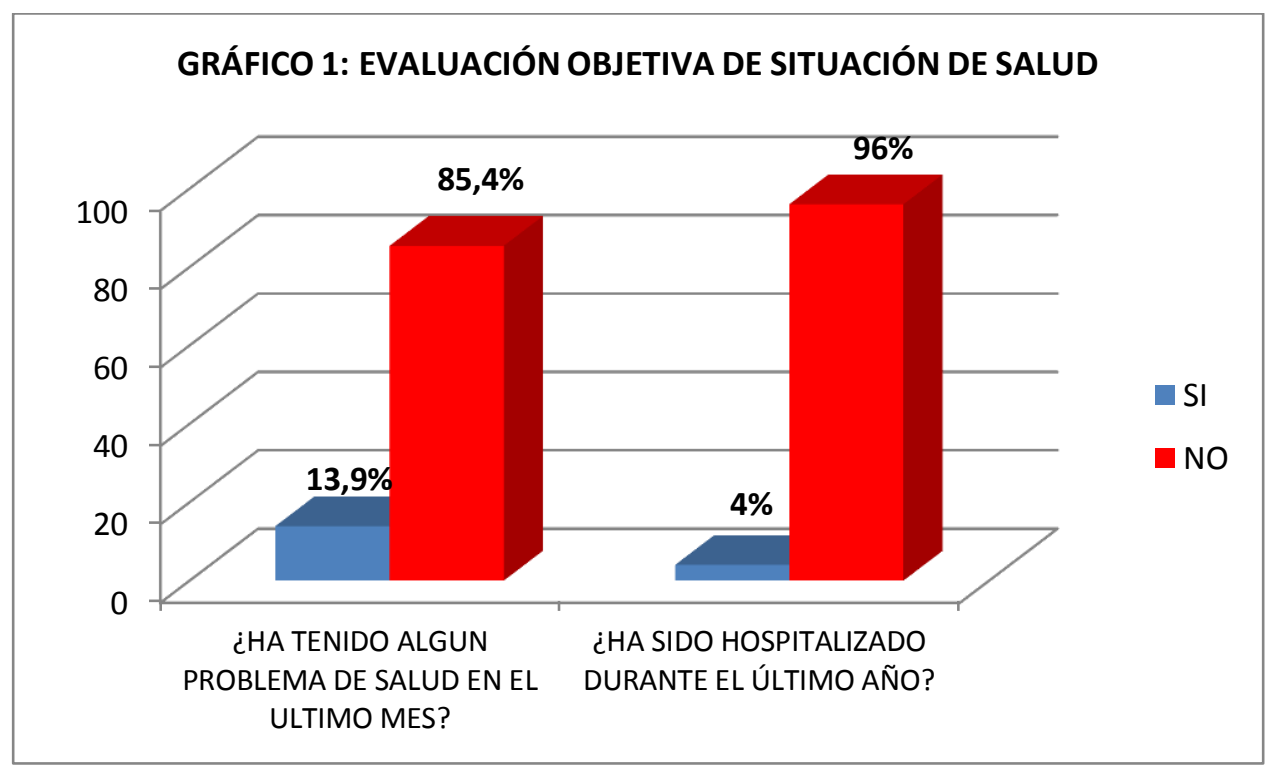

Respecto de la evaluación subjetiva de la vida de los talquinos, la evidencia empírica indica que la percepción es eminentemente positiva, puesto que el $80 \%$ considera su estado de salud como "bueno", mientras que el $81,4 \%$ se considera satisfecho o muy satisfecho con su estado de salud. 


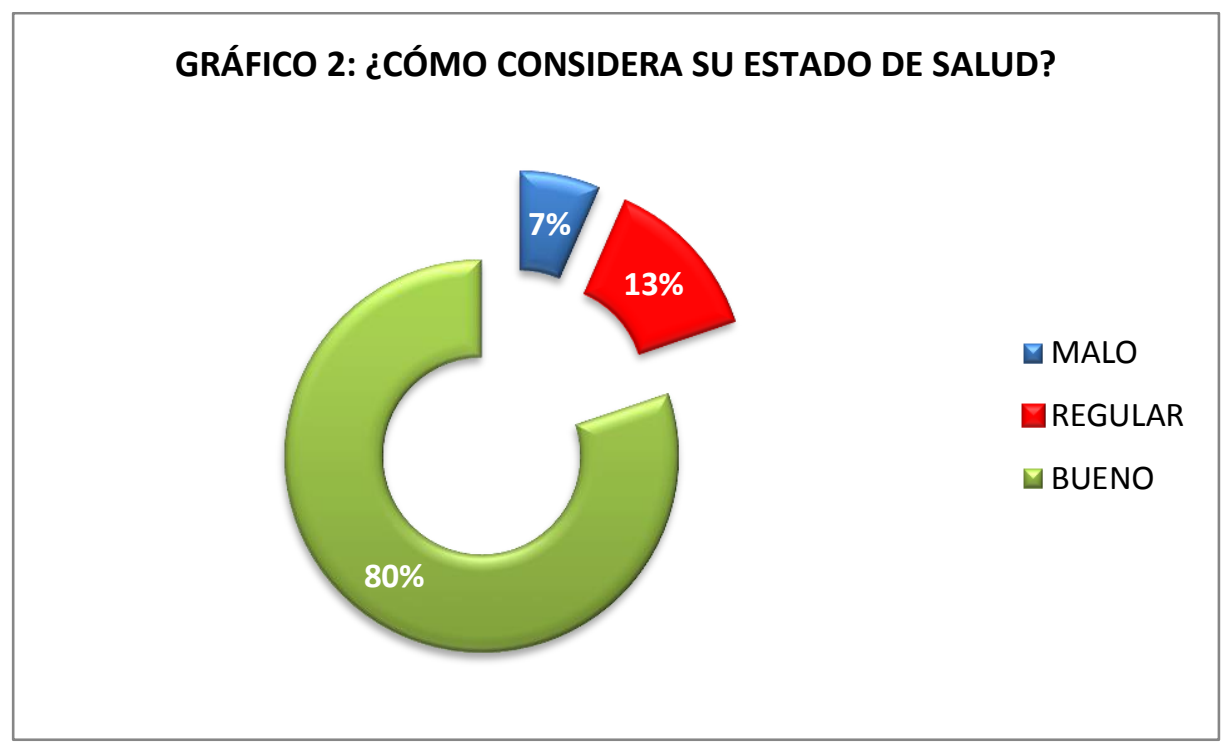

GRÁFICO 3: ¿QUÉ TAN SATISFECHO/A ESTÁ CON SU ESTADO DE SALUD?

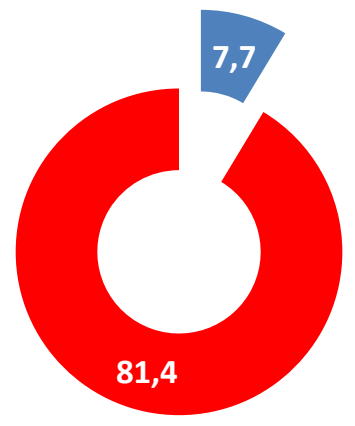

- INSATISFECHO

- SATISFECHO

Respecto de la percepción de los talquinos en cuanto al acceso a los servicios médicos de la comuna prácticamente 7 de cada 10 talquinos se considera satisfecho, no obstante 1 de cada 4 evalúa la calidad de los recintos de salud negativamente (mal o muy mal), mientras que 1 de cada 3 percibe que la disponibilidad de médicos especialistas es insuficiente (mal o muy mal). 

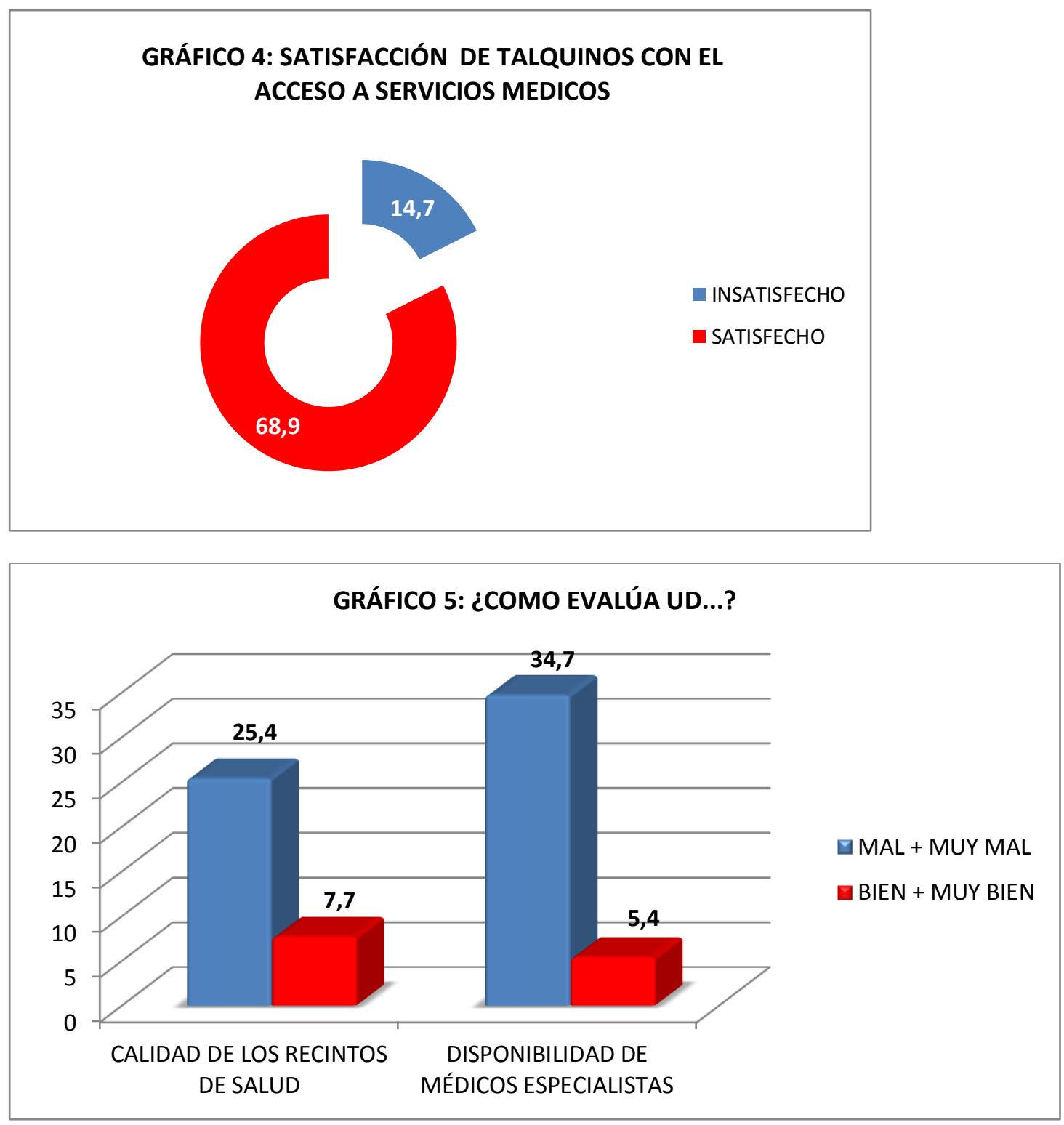

Como síntesis de este primer módulo, se percibe que los talquinos en rigor gozan de buena salud (dimensión objetiva) y se sienten satisfechos con su estado de salud (dimensión subjetiva), como también con el acceso a los servicios de salud comunales, siendo los puntos bajos la infraestructura de estos recintos de salud y también el déficit de médicos especialistas para cubrir adecuadamente la demanda. Se espera que la percepción deficiente respecto de los recintos de salud y del déficit de médicos especialistas mejore una vez que el hospital de Talca entre en funcionamiento. 


\section{MODULO 2: EMPLEO}

El segundo módulo evaluado se refiere al empleo, considerando para ello la medición de variables objetivas y subjetivas, siguiendo la tónica de este estudio. Los seres humanos pasamos diariamente nueve horas o más en nuestros trabajos, siendo la actividad laboral aquella que demanda más horas de nuestro tiempo, aparte de la actividad educativa, durante nuestras vidas. De este modo, es altamente deseable que las tareas que desempeñamos en el trabajo sean gratificantes y las relaciones humanas que mantenemos con nuestros colegas sean, al menos, cordiales y respetuosas.

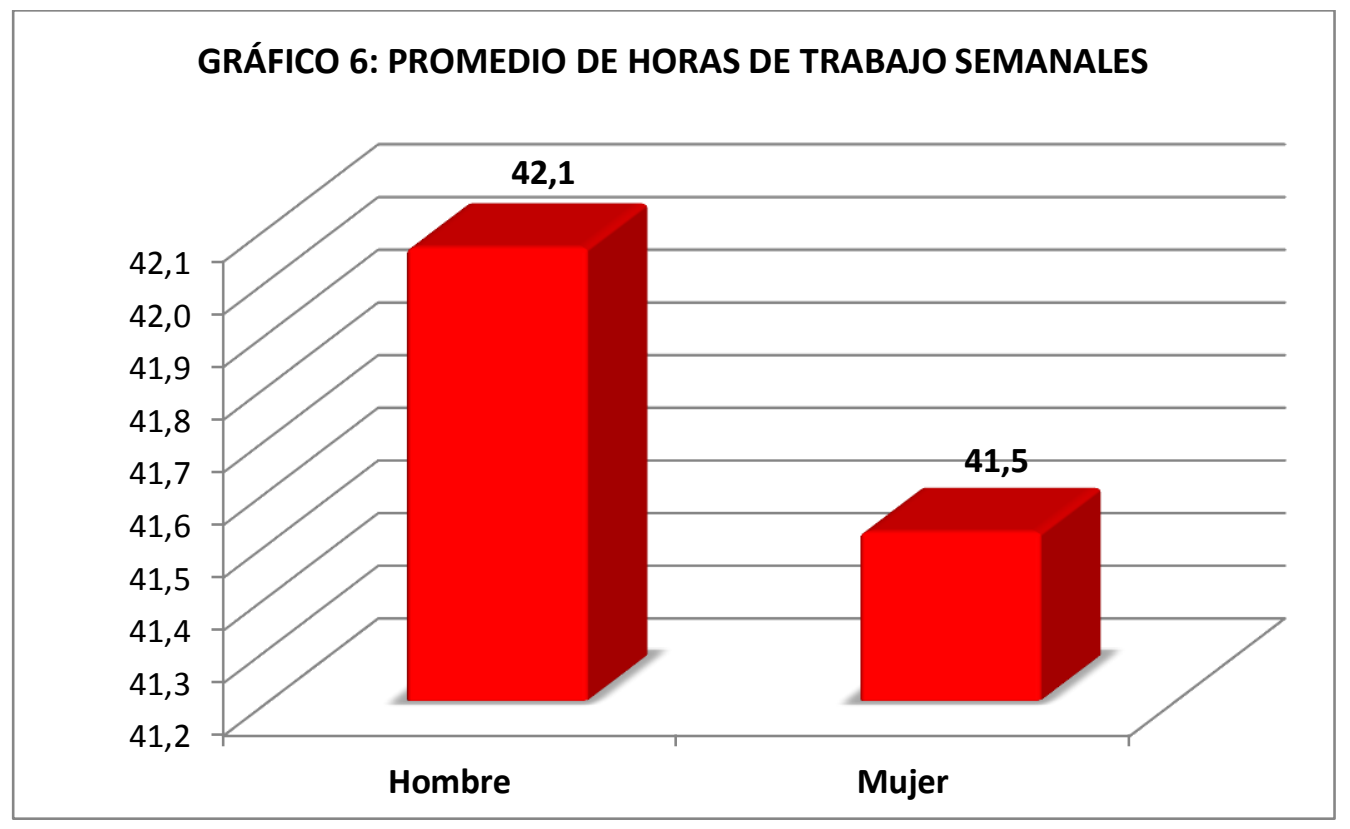

Una primera constatación refiere a la cantidad promedio de horas trabajadas semanalmente por los talquinos y talquinas, donde se aprecia que hombres en promedio trabajan 0,6 horas más que las mujeres a la semana. Según la ocupación desempeñada, se constata que quienes trabajan como asesoras de hogar "puertas adentro" son quienes en promedio trabajan más horas a la semana, mientras que las asesoras de hogar "puestas afuera" son quienes trabajan menos horas semanales promedio. 


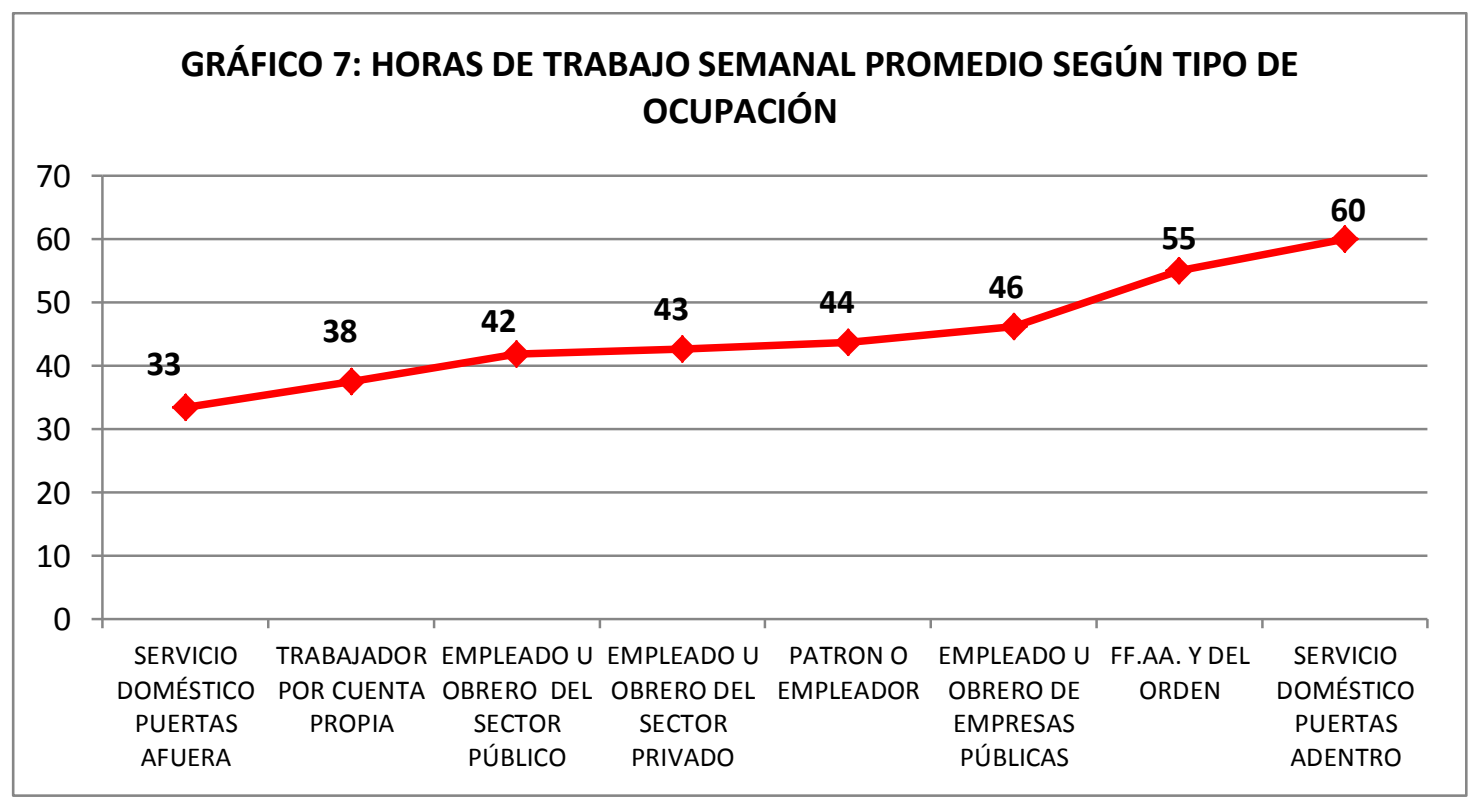

Con respecto a la situación previsional de talquinos y talquinas, el estudio revela que prácticamente el $70 \%$ de quienes trabaja se encuentra afiliado a algún sistema de cotización previsional y de aquel porcentaje, el $61 \%$ se encuentra cotizando al día.

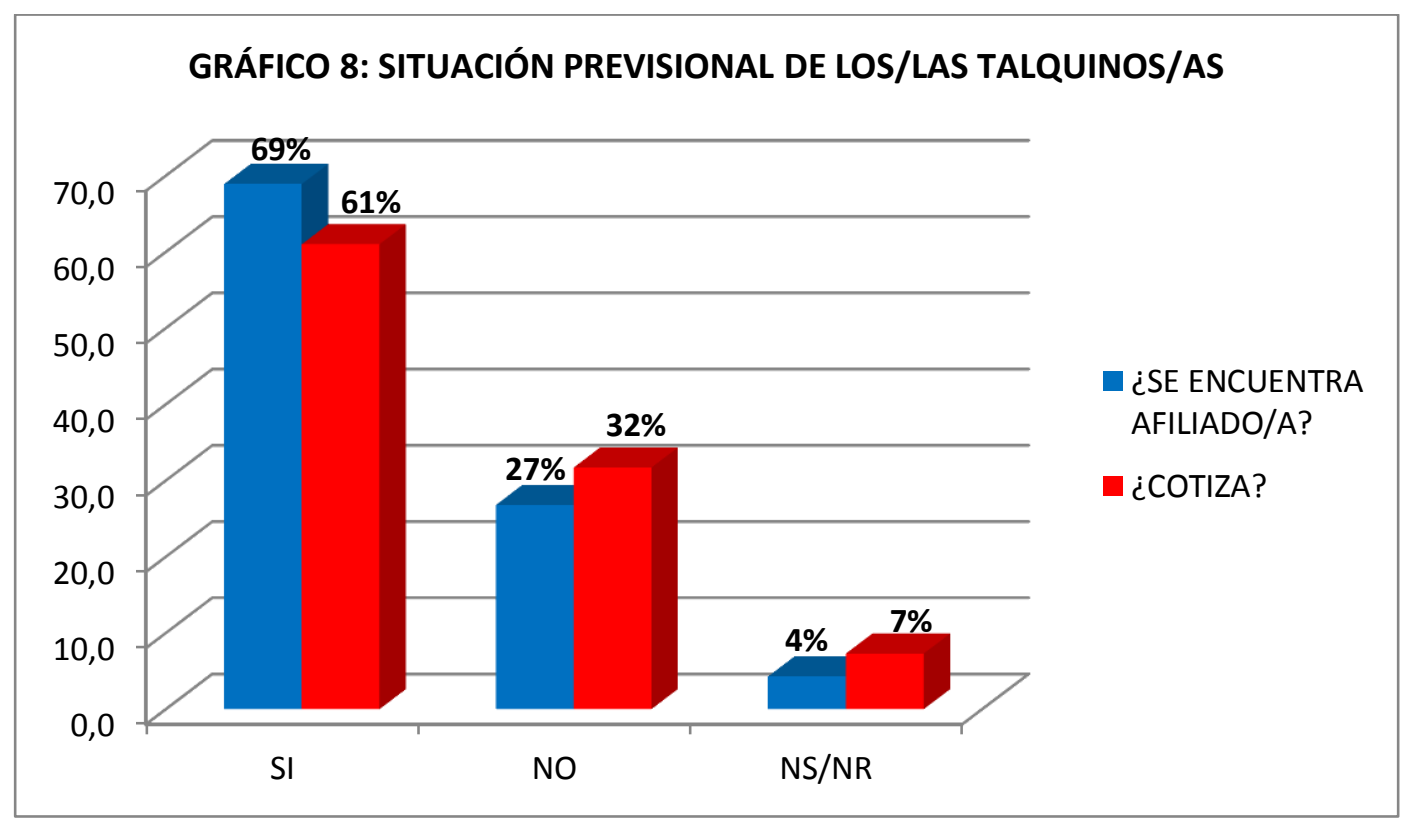




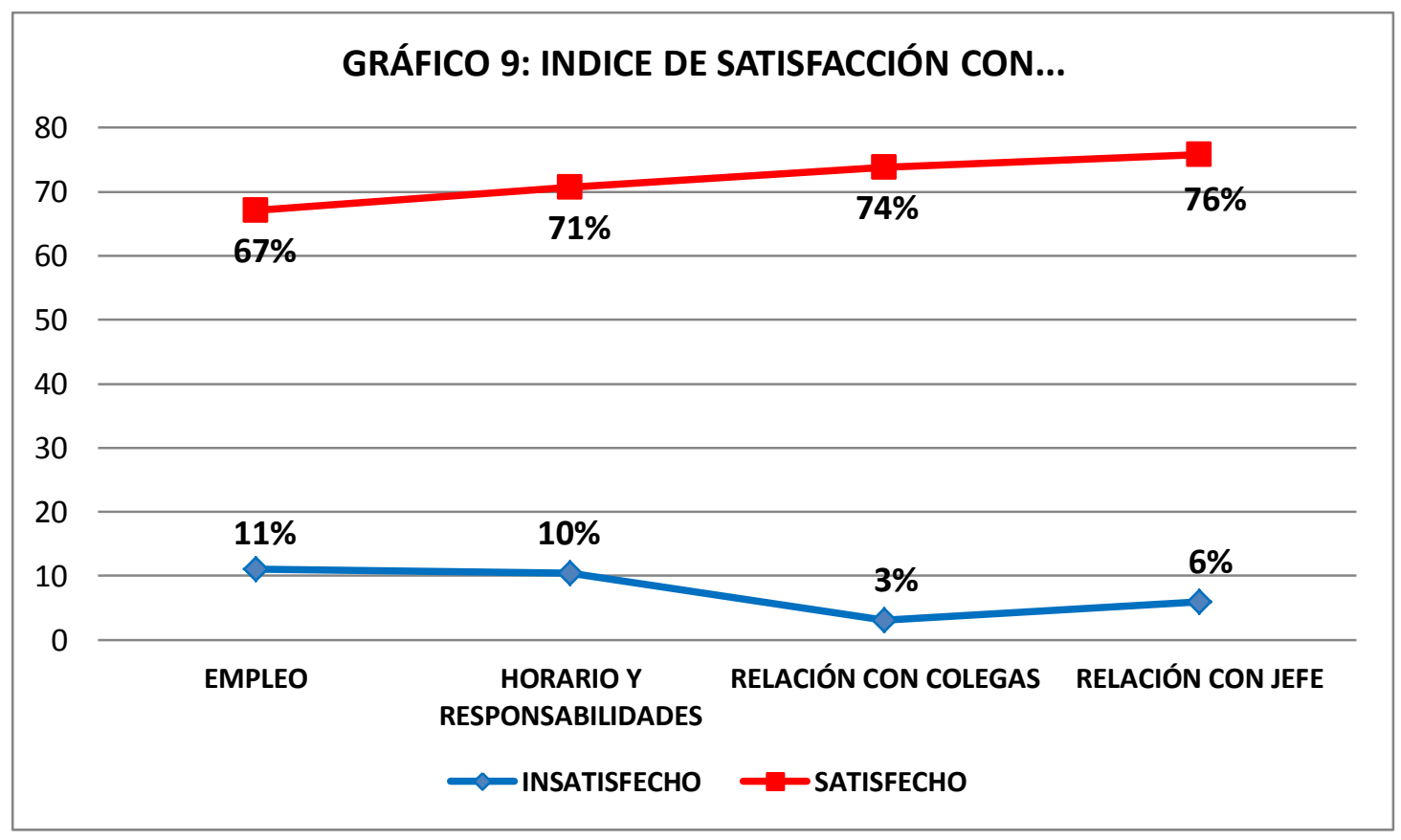

Finalmente, en relación con los aspectos subjetivos de la actividad laboral de talquinos y talquinas, se constata que existe mayor satisfacción con las relaciones laborales con los colegas y el jefe que con las responsabilidades y tareas propias de la actividad laboral en sí misma. 


\section{MODULO 3: INGRESOS}

Los ingresos económicos son consustanciales a la autonomía de los individuos y las familias en sociedad, permitiendo satisfacer necesidades vitales, como la alimentación, materiales, como vivienda, e inmateriales tales como el consumo cultural.

El ingreso familiar mensual promedio de los talquinos es de \$ 528.105 (considerando salarios, subsidios, pensiones y otros tipos de ingresos), el promedio de miembros por familia es de 3,6 personas, por lo tanto, el ingreso per cápita promedio es de $\$ 148.762$.

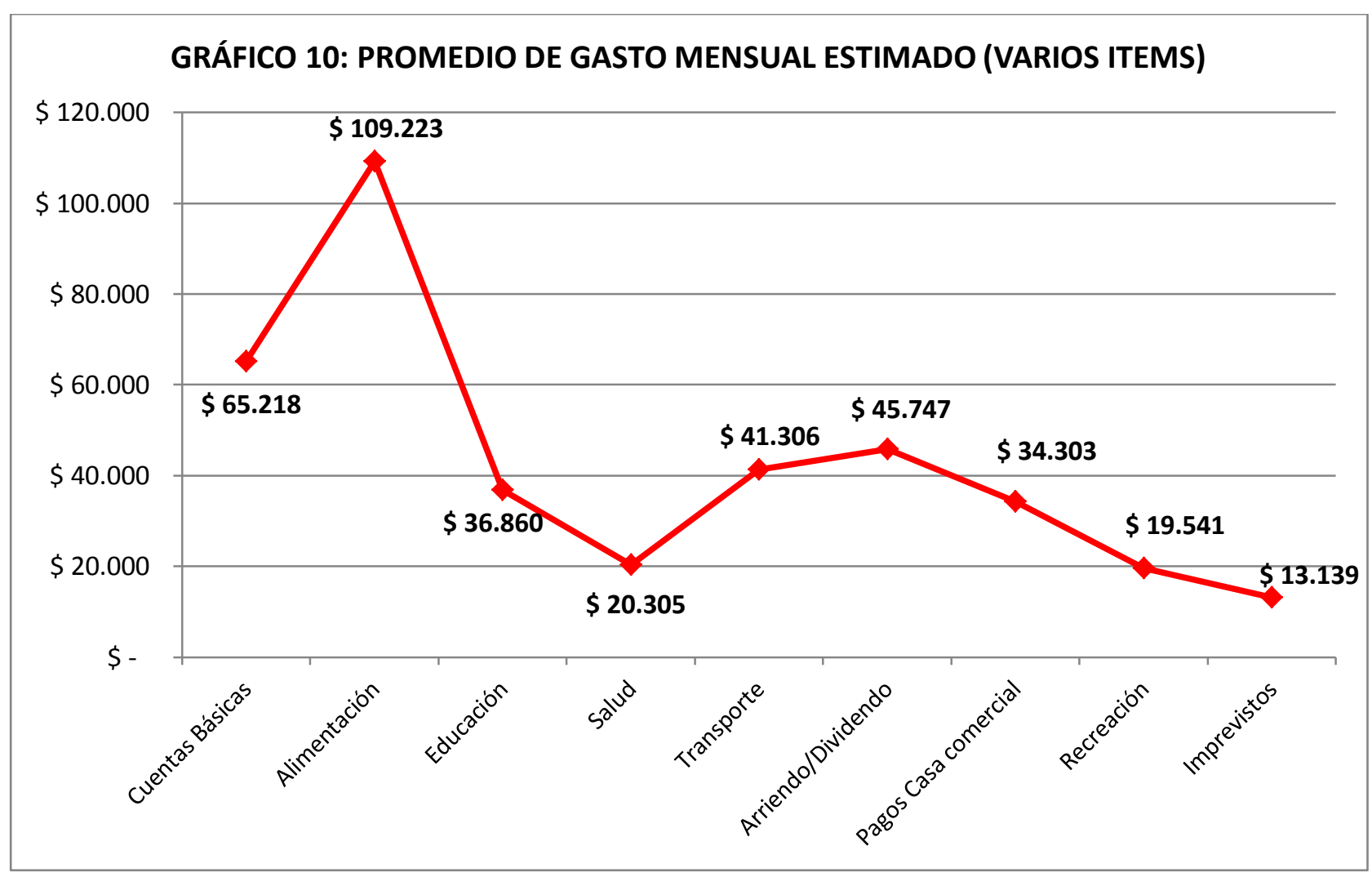

Los ítems de gasto principales para los talquinos son: Alimentación, Pago de Cuentas Básicas (agua, luz, gas, etc), Pago de Arriendo/Dividendo y Transporte, los cuales, en conjunto constituyen aproximadamente el $70 \%$ del presupuesto mensual. 


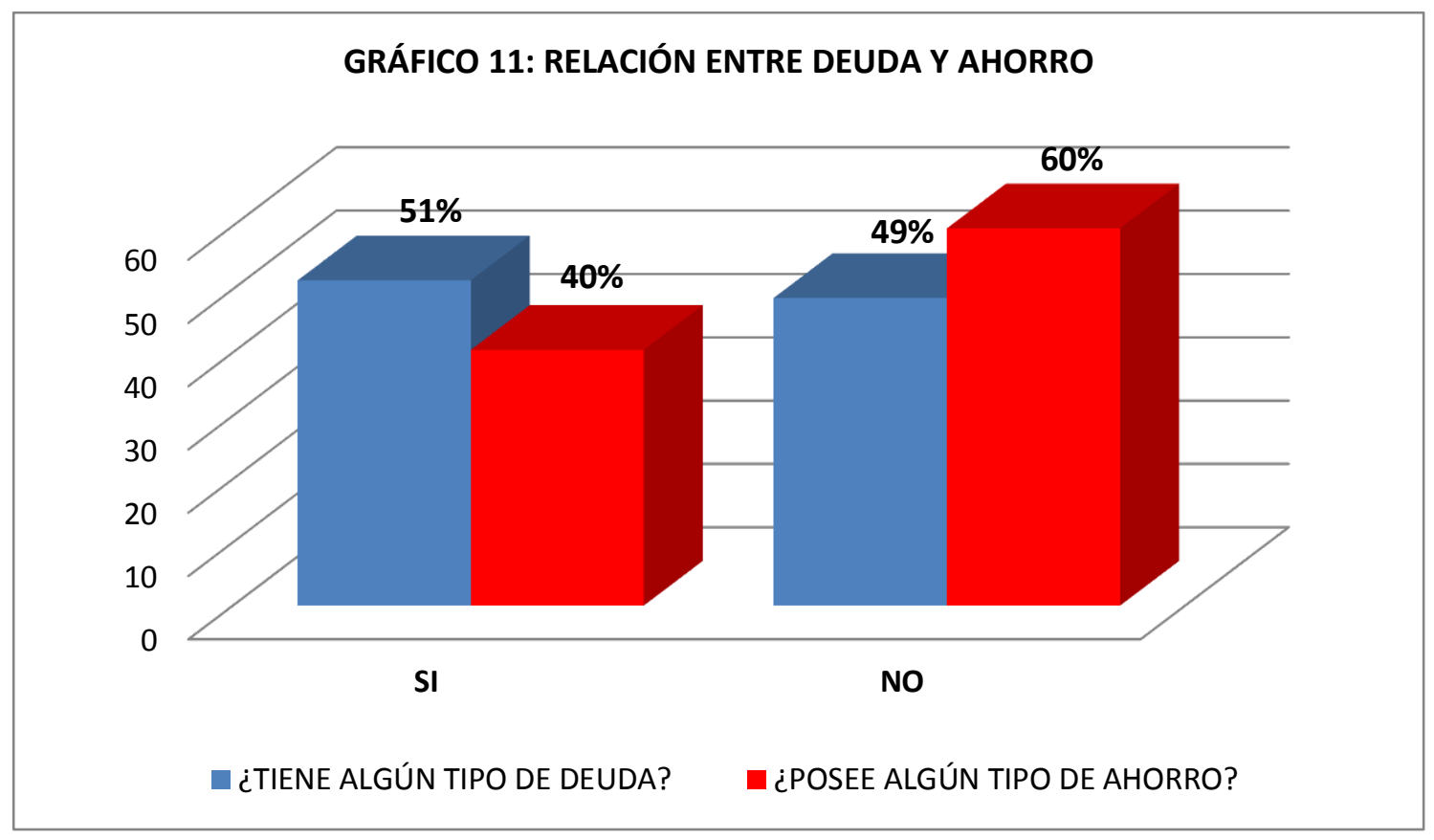

Ahora bien, y como es de suponer de la relación deuda/ahorro se inclina hacia la primera, pues el $51 \%$ de los entrevistados declara tener algún tipo de deuda (ya sea de tipo financiero, o a través de préstamos informales), mientras que solo el $40 \%$ señala poseer algún tipo de ahorro, siendo la relación entre ambas 1,25 veces mayor la deuda que el ahorro.

En relación con la dimensión subjetiva respecto de la satisfacción de los talquinos con sus ingresos monetarios y su real capacidad de ahorro y gasto, tenemos que en una escala de 1 ("muy insatisfecho") a 5 ("muy satisfecho"), el aspecto peor evaluado es la capacidad de ahorro con 2,9 puntos (lo cual representa un nivel de insatisfacción moderado) y el aspecto mejor evaluado es condiciones de su vivienda con 3,8 puntos (lo cual representa un débil nivel de satisfacción). 


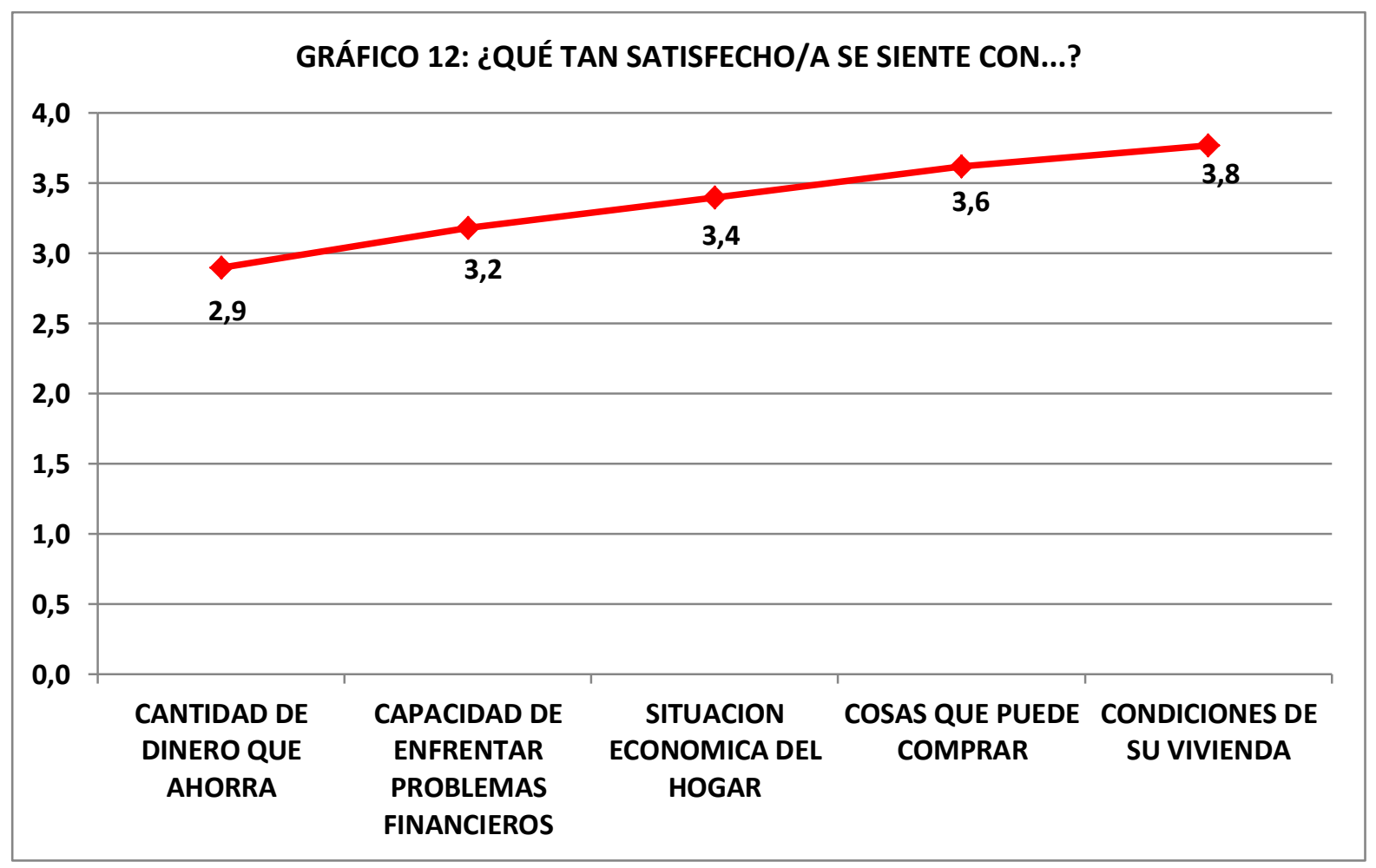

En síntesis, la familia talquina percibe en promedio poco más de $\$ 500.000$ mensuales, considerando una cantidad de miembros de 3,6 personas, aquello indica un ingreso per cápita promedio aproximado de $\$ 150.000$. Prácticamente el $70 \%$ de los ingresos familiares son gastados en necesidades básicas (alimentación, cuentas, vivienda y transporte) La capacidad de ahorro es escasa y, por cierto, el nivel de endeudamiento es mayor 1,25 veces el ahorro, puesto que el $51 \%$ declara tener algún tipo de deuda pero solo el $40 \%$ posee ahorros. Finalmente, en cuanto a la satisfacción de los/as talquinos/as respecto de su situación financiera familiar, se advierte que la menor satisfacción es precisamente con la capacidad de ahorro, mientras que el mayor nivel de satisfacción son las condiciones de la vivienda. 


\section{MODULO 4: FAMILIA}

Numerosas teorías sociales plantean que la familia es el núcleo de la sociedad, por lo tanto, la conservación de la estructura "clásica" o "tradicional" familiar es una <<conditio sine qua non>> para preservar la supervivencia misma de la sociedad. Sin embargo, es un hecho sabido que la estructura familiar tradicional se ha abierto a diversas posibilidades constitutivas, cada una de ellas con dinámicas propias las cuales son síntoma de la sociedad moderna. No obstante, más allá de la forma que defina la estructura familiar, lo que sigue siendo cierto es que valores tales como el respeto y la tolerancia, entre muchos otros, son fundamentales para garantizar su preservación a lo largo del tiempo. En un contexto de vida en el que se privilegia el trabajo por sobre las relaciones familiares, es que esta dimensión se torna fundamental para los sujetos al momento de evaluar su bienestar individual.

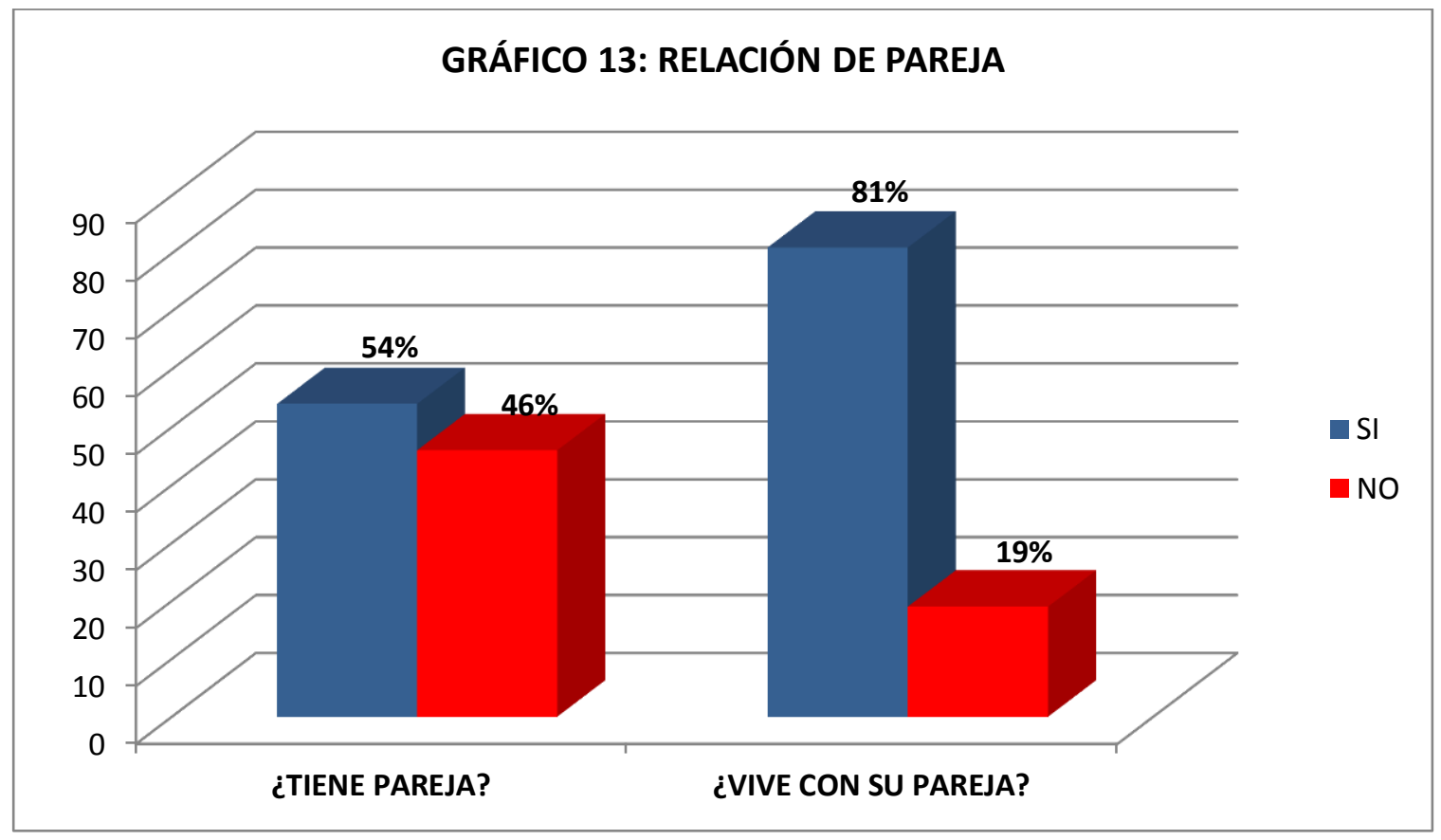

Dicho lo anterior, una primera constatación referida a este módulo es que el 54\% de los talquinos tiene pareja $y$, de aquella cifra, quienes viven con su pareja alcanzan el $81 \%$. Ahora bien, el estado civil o situación legal en que se encuentran las parejas que viven bajo el mismo techo mayoritariamente corresponde a "matrimonios" a pesar que la proporción de parejas "convivientes" es bastante cercana. Esta es una primera señal acerca de la forma de la estructura familiar talquina. 


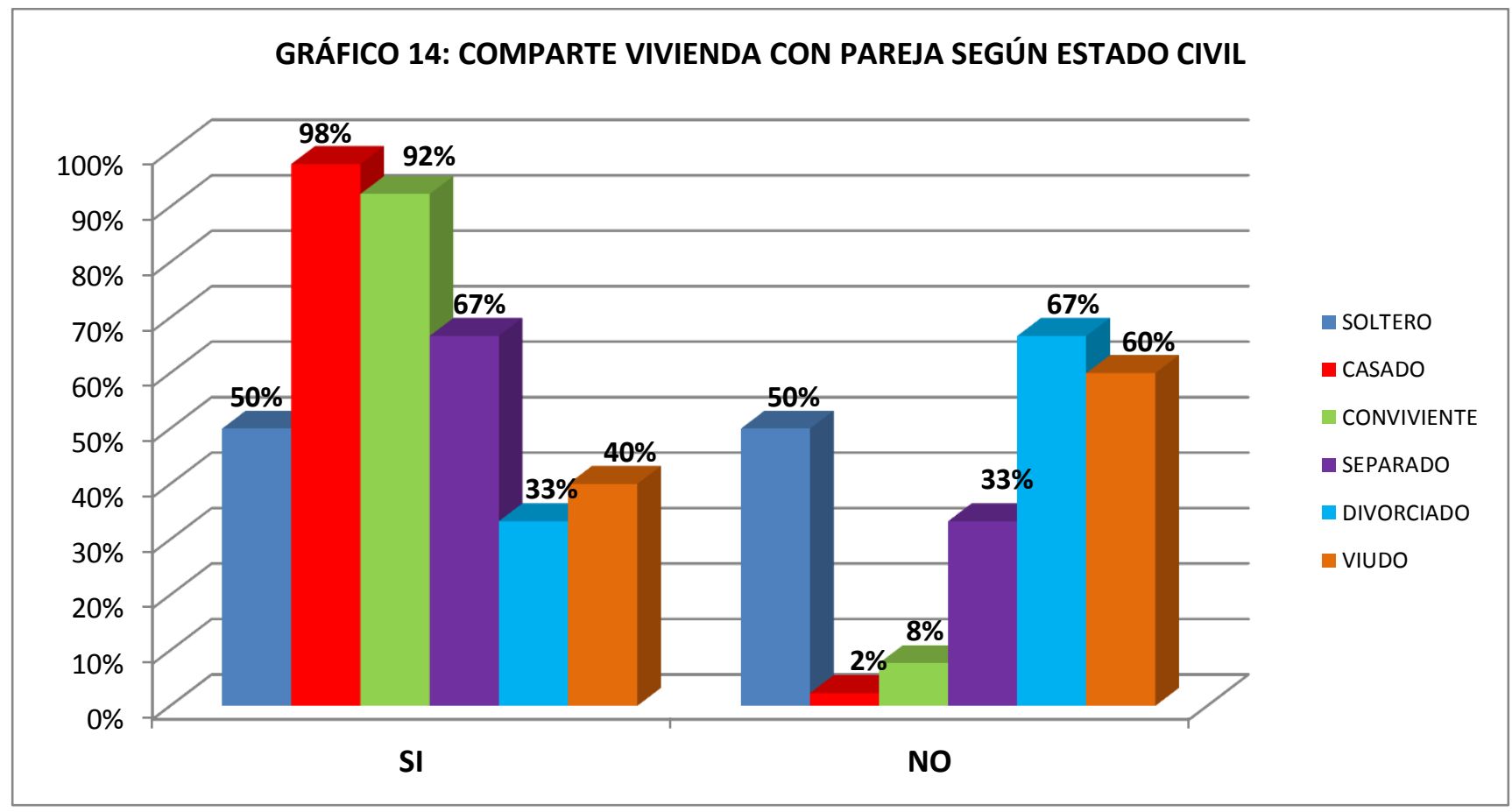

Luego, respecto del hábito de realización de ciertas acciones familiares los talquinos, destaca con más frecuencia el "comer juntos" (89\% lo hace habitualmente o frecuentemente). Sin duda que esta es una acción familiar fundamental, pues es en este espacio que los miembros de la familia conversan y se enteran del curso de la vida cotidiana de cada cual, lo cual, dado el vertiginoso ritmo de vida de las grandes ciudades hoy en día, se puede considerar esta acción familiar colectiva prácticamente como un privilegio de vivir en ciudades más pequeñas. 


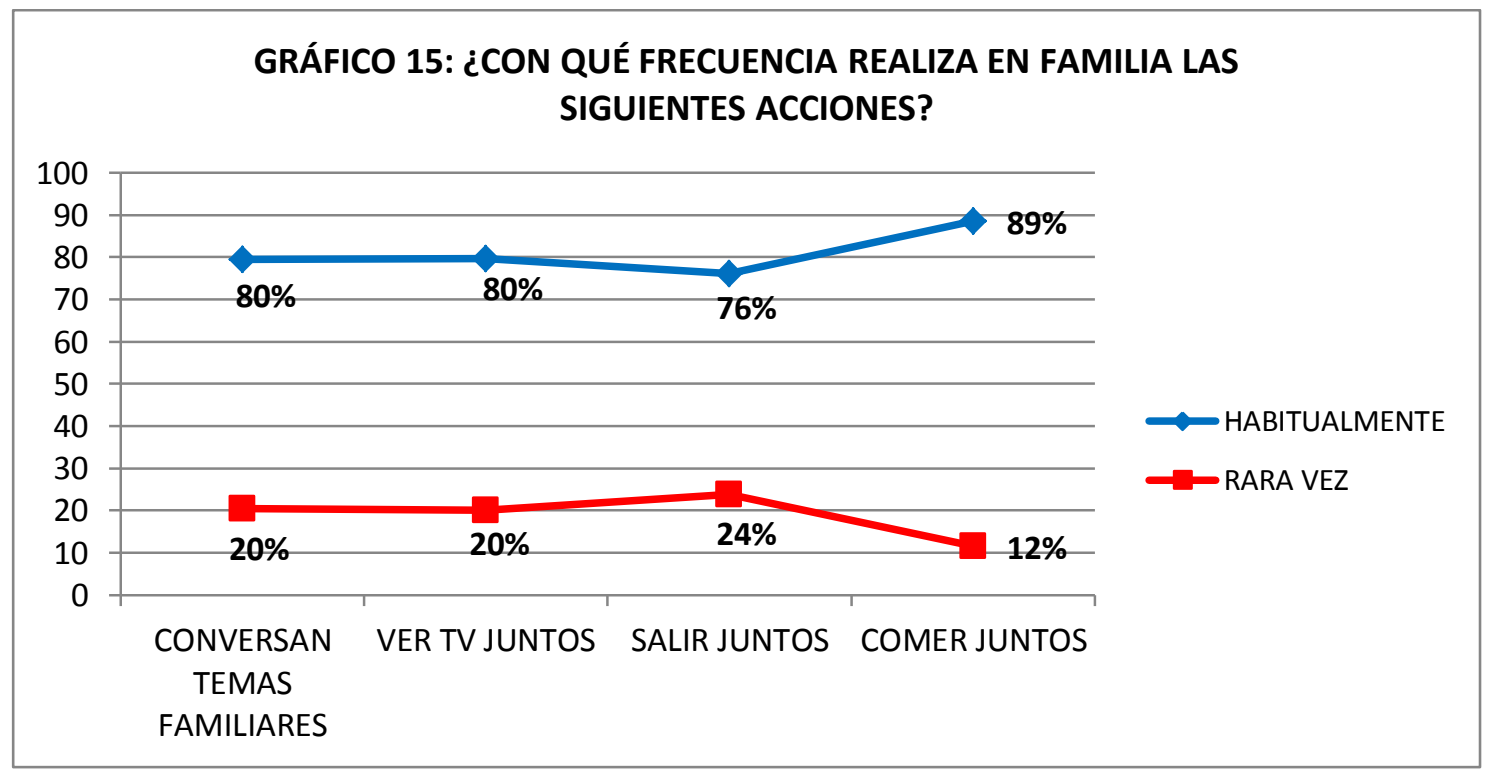

Finalmente, aunque con escasos tres puntos porcentuales de diferencia, se manifiesta el mayor grado de satisfacción con los padres y el más bajo con los hijos. No obstante la satisfacción con los miembros de la familia supera largamente el $80 \%$.

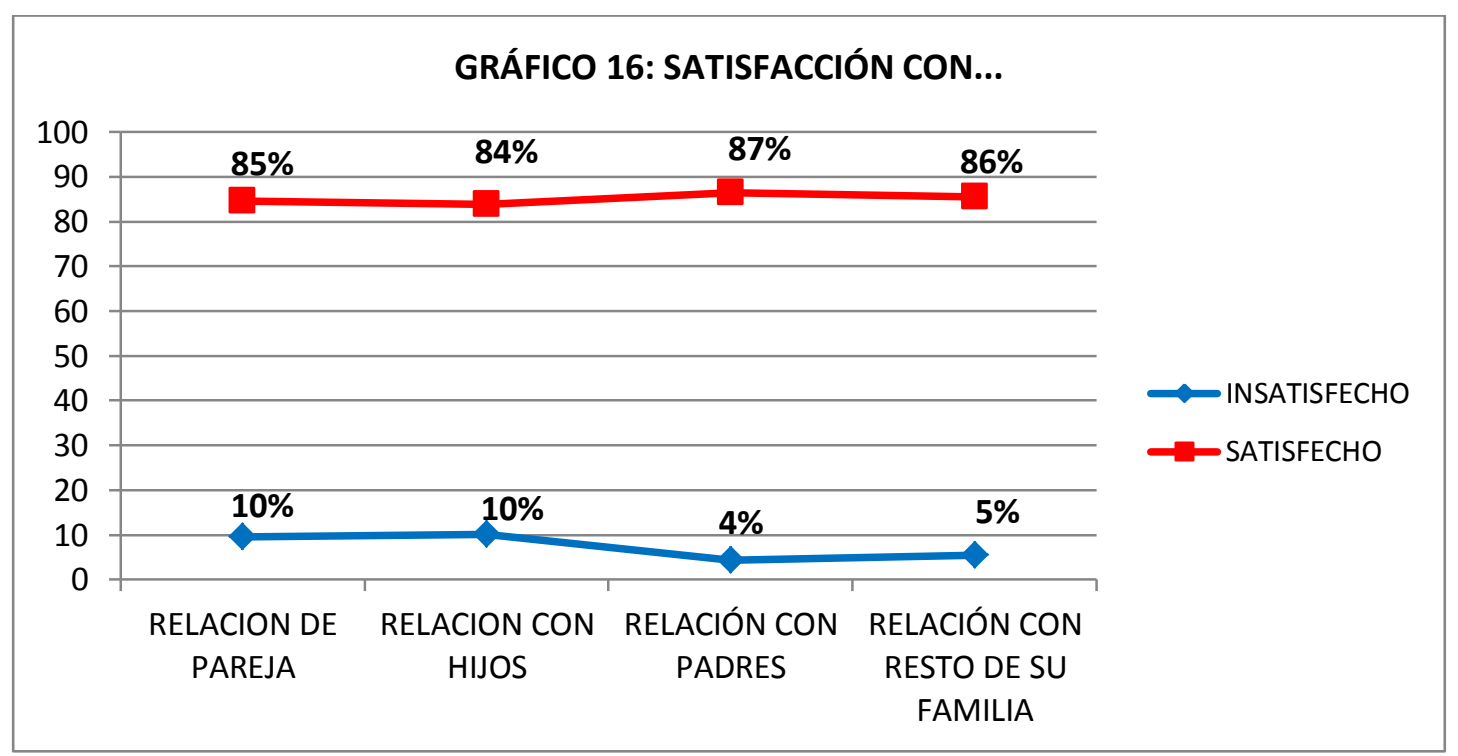




\section{MODULO 5: AMISTAD Y REDES SOCIALES}

La consolidación de relaciones de amistad es una práctica sociocultural propia de nuestra idiosincrasia latinoamericana, convirtiéndose las amistades prácticamente en una extensión de la vida familiar nuclear. Dado que en la actualidad las familias son cada vez más pequeñas, el cultivo de la amistad y las buenas relaciones personales se torna en un capital fundamental con que disponemos y que se traduce en el intercambio de favores, ayuda y apoyo material y socio-afectivo: en la teoría social este intercambio se conoce como capital social. Producto de situaciones propias al ciclo vital y a nuestra vida social misma, las amistades van disminuyendo con el tiempo, siendo los contextos de estudio (enseñanza básica, media y superior) probablemente los espacios socioculturales en los que contamos con una amplia cantidad de amigos, los cuales se irán reduciendo a medida que avanzamos en el ciclo vital.

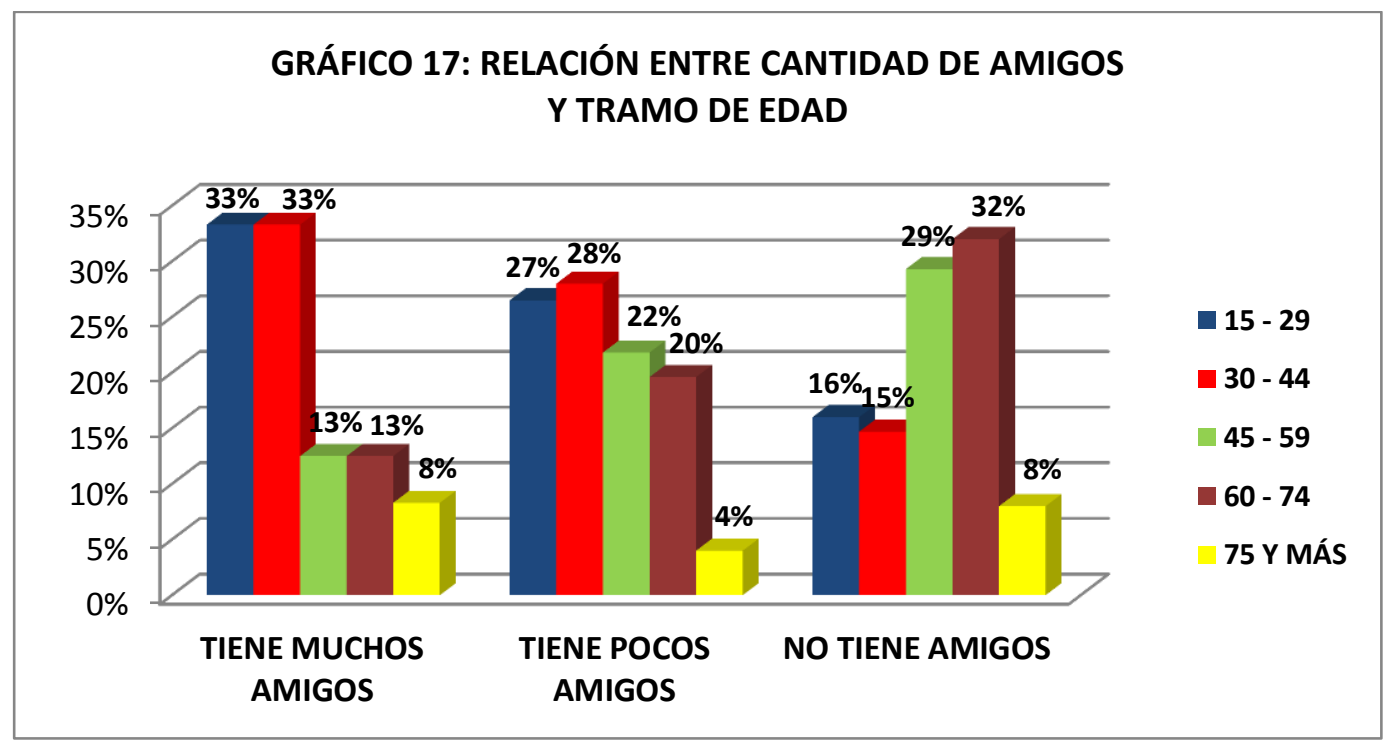

El gráfico anterior refleja precisamente lo que estamos señalando, en el sentido que los grupos de edad que señalan tener muchos amigos son el considerado "joven" (15 a 29 años) y "adulto joven" (30 a 44 años), en cambio quienes declaran no tener amigos se advierte que el "grupo adulto mayor" (60-74 años) es el que representa la mayor cantidad de personas sin amistades, lo cual, en el caso de este último grupo, reviste de mayor preponderancia pues muchos adultos mayores terminan viviendo en soledad en una etapa del ciclo vital que requieren redes de apoyo afectivo y de apoyo económico. 


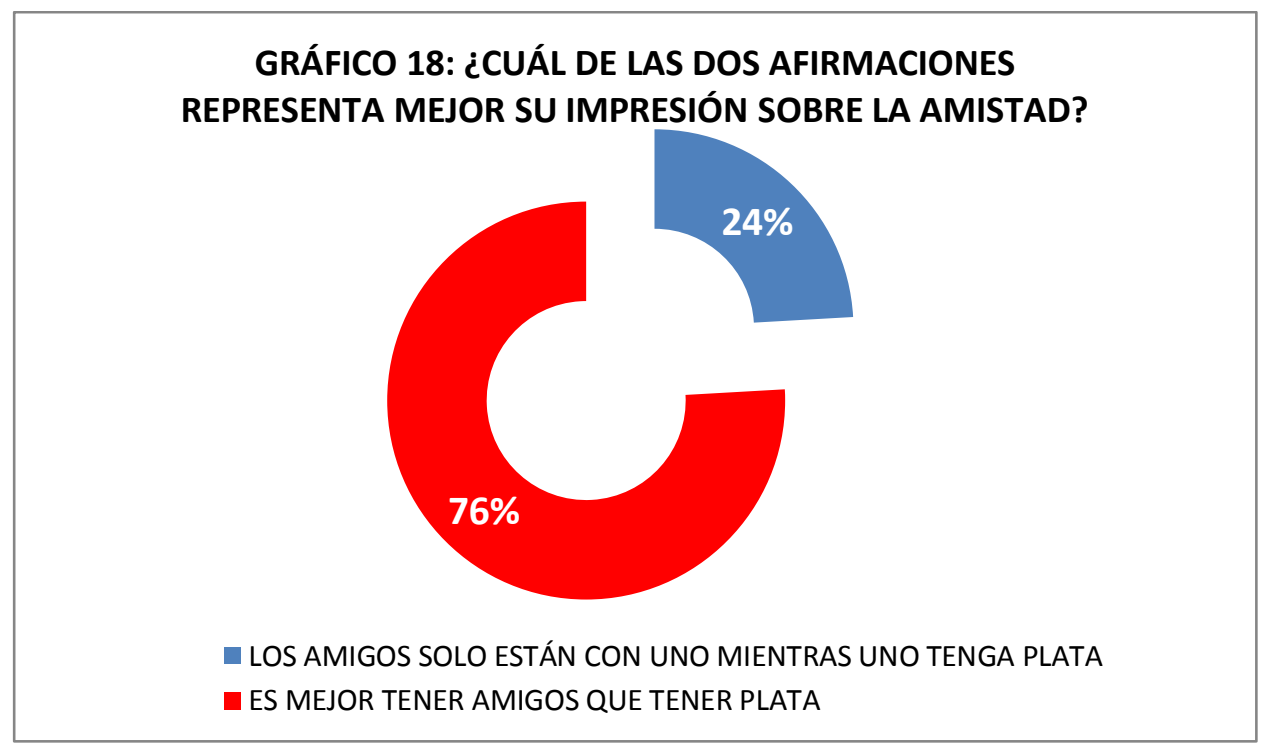

El reconocimiento de la importancia de la amistad en la vida social se refleja en el gráfico anterior, en el cual se aprecia que para la mayoría de los talquinos y talquinas "es mejor tener amigos que tener plata" (76\%).

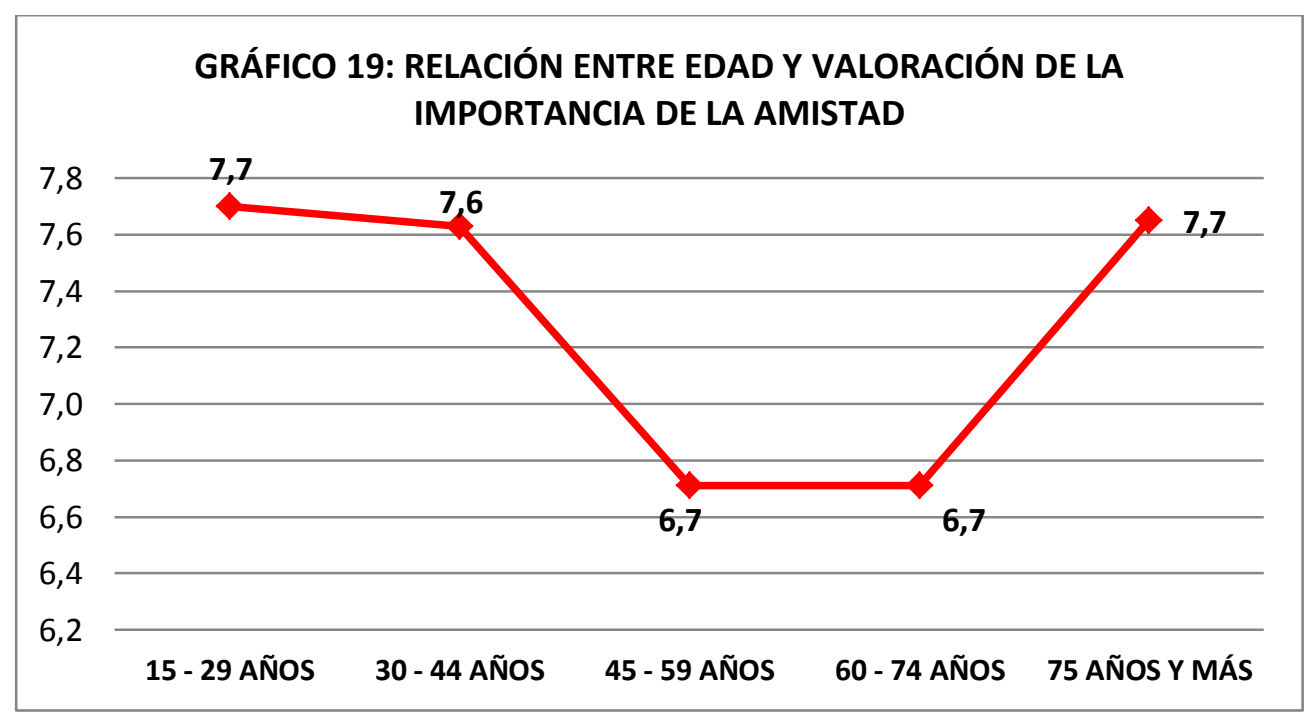

Se le pidió a los encuestados que valoraran en una escala de 0 a 10 la importancia que le atribuían al tener amigos en la vida, siendo 0 "nada importante" y 10 "extremadamente importante". Según se advierte en la gráfica, la puntuación promedio refleja un brusco descenso en dicha valoración en los grupos de edad de 45 a 59 años y 60 a 74 años, aumentando nuevamente en el grupo de mayor edad (75 años y más). La explicación de este fenómeno puede ser el hecho que para los dos primeros tramos la mayor densidad y frecuencia de las relaciones sociales incida en la valoración positiva, en cambio en los tramos siguientes la experiencia 
social determina que la vida social tiende a disminuir y a concentrarse más en la familia nuclear. Posteriormente, en el último tramo de vida, en muchos casos ante el alejamiento de la familia nuclear las amistades se transforman en una compañía y apoyo socio-emocional fundamental, como lo suele ser, por ejemplo, en el caso de los asilos de ancianos.

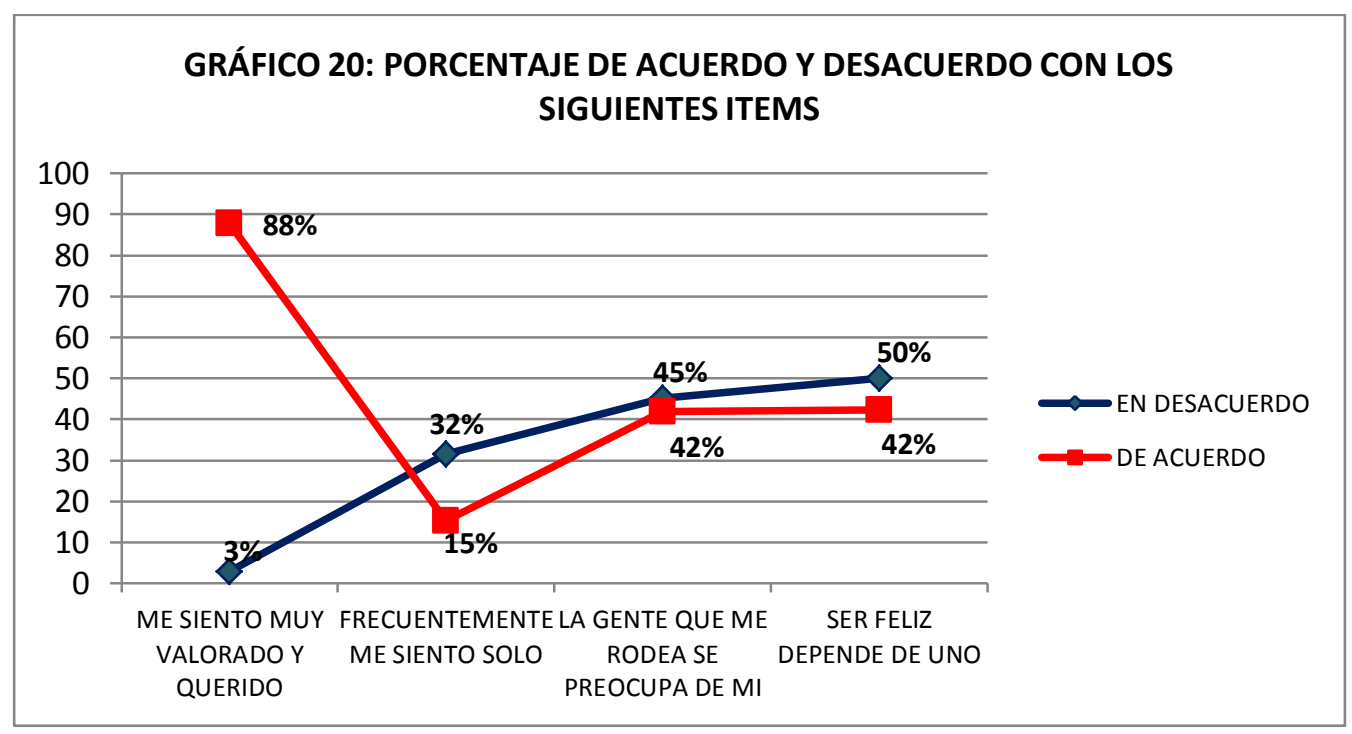

En la gráfica anterior existe una suerte de contrasentido en la respuesta de los entrevistados, pues por una parte el $88 \%$ se siente "muy valorado y querido", no obstante la mayoría "se siente solo(a) con frecuencia" (32\%), no siente que "la gente que les rodea se preocupa de ellos" (45\%) y la mitad no cree que "la felicidad depende de uno mismo" (50\%).

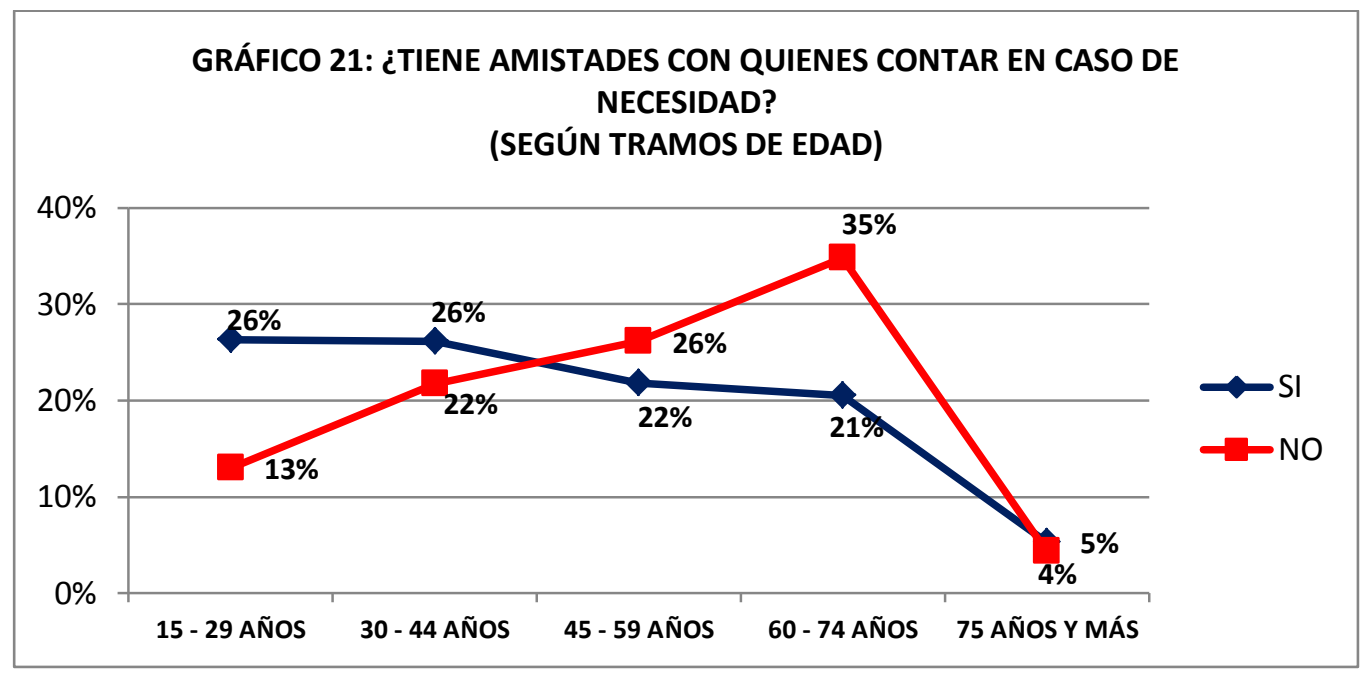

La evidencia reportada por el gráfico 21 permite conectar la información con la revisada en el gráfico 19, entendiendo, como ya señalamos, que la valoración de la importancia de la amistad desciende entre los tramos "45 a 59" y "60 a 75 años" el 
gráfico 21 en cuestión evidencia que aquellos segmentos etarios declaran "no contar con amistades en caso de necesidad", cuestión que explica su pesimismo en relación con la valoración de la importancia de las amistades.

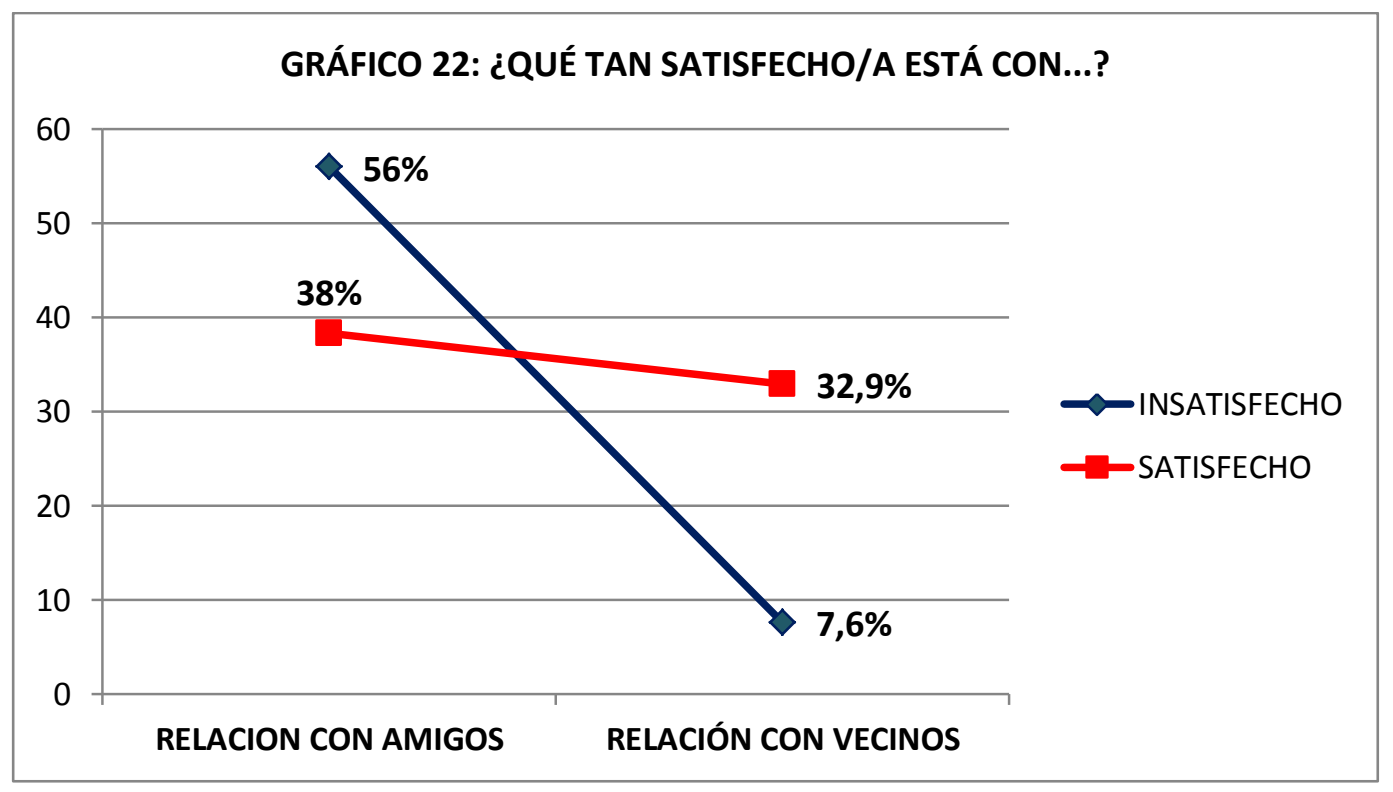

Finalmente, se advierte un porcentaje amplio de personas que están insatisfechas con sus amistades (56\%) en contraposición con el bajísimo $7,6 \%$ que manifiesta insatisfacción con sus vecinos.

En síntesis, aun cuando los talquinos reconocen y valoran la importancia de la amistad como parte fundamental del quehacer social, existen diferencias en esta valoración dependiendo del ciclo vital de las personas. Así entonces, se constata que para los "jóvenes" y "adultos jóvenes" las amistades son más importantes que para los "adultos" y para los "adultos mayores", siendo una explicación posible el hecho de que estos últimos segmentos declaran no contar con amistades en caso de necesidad. 
Las personas nacemos y nos desarrollamos en el seno de una comunidad. Nuestra "comunidad inmediata" corresponde al sector de residencia, que va a determinar nuestras primeras amistades infantiles $y$, por tanto, va a influir en nuestro proceso de socialización temprano. Luego, se identifica la comuna donde vivimos, en la que nos educamos y trabajamos y, en definitiva, la cual nos provee de los servicios básicos ( $y$ de todo tipo) que utilizamos a diario. En un tercer nivel se encuentra el referente nacional, a nivel país, que nos brinda la nacionalidad y también parte importante de nuestra idiosincrasia. De esta manera, en estos tres niveles de comunidad interactuamos permanentemente y de manera indistinta, pues así como pertenecemos a la comunidad nacional, también somos parte del territorio local que comprende nuestra comuna y en ella, nuestro sector de residencia. Ahora bien, en lo cotidiano, nuestra acción inmediata ejerce influencia directa en nuestro sector de residencia, por ejemplo, cuando decidimos ser parte de la junta de vecinos de nuestro sector y apoyamos la toma de decisiones que favorezca la realización de ciertas obras que nos impacta directamente, por ejemplo, la construcción de una plaza. Pero también ejercemos influencia en el entorno local y nacional cuando elegimos a nuestros representantes políticos, aunque de manera indirecta. Por lo anterior, en cuanto ciudadanos, ejercemos influencia por la sociedad de la que formamos parte $y$, a su vez, también somos moldeados por ella y por el conjunto de valores, normas sociales y leyes que regulan la convivencia en sociedad. De esta manera, para participar de la vida cívica y comunitaria es fundamental sentirse integrado y respetado en dignidad y derechos, de lo contrario resulta difícil imaginar una convivencia armónica en sociedad.

Es precisamente esto último que mide la variable representada por el gráfico 23, en el cual es posible advertir que solo el $21 \%$ de los talquinos cree que en esta sociedad se respetan su dignidad y sus derechos (muy de acuerdo + de acuerdo), es decir, si lo planteamos en términos de proporciones, tan sólo uno de cada cinco talquinos cree que su dignidad y sus derechos son respetados en nuestra sociedad. Lo anterior se complementa con el Informe de Desarrollo Humano Chile 2012 (IDH, 2012) el cual señala que existe un alto bienestar subjetivo individual, pero, a su vez, también un elevado malestar subjetivo con la sociedad. Esto se explicaría porque los individuos operamos solo en cuanto consumidores en el "mercado", el cual, a su vez, pasa a ocupar todos los espacios de la vida social: lo anterior ha generado una serie de problemas de abusos de parte de empresas con acciones al filo de lo legal (caso La Polar) y en algunos casos también del propio estado que ha pasado a llevar a los ciudadanos, siendo un claro ejemplo de ello el sistema de transporte público metropolitano "transantiago". 


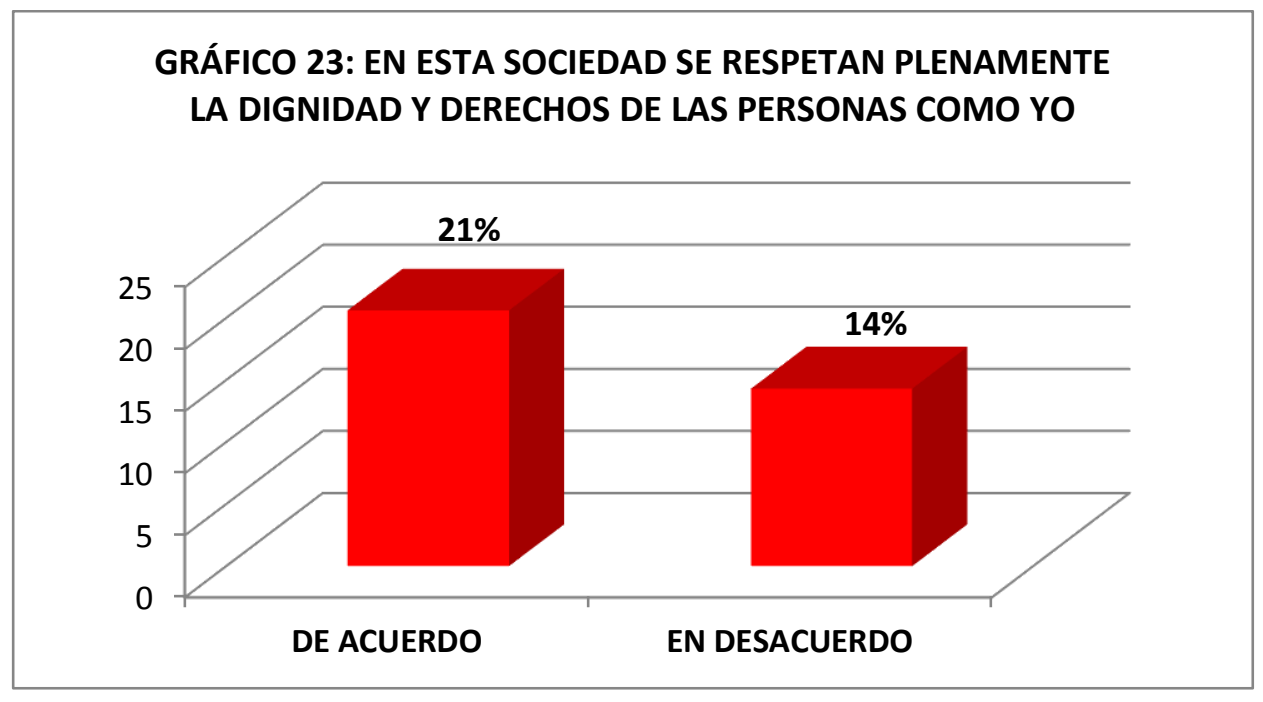

Ahora bien, enfocándonos en el entorno residencial y comunal de los talquinos respecto a la valoración de servicios varios, en general existe una alta valoración positiva en torno al barrio mismo de residencia y a los servicios disponibles en su entorno.

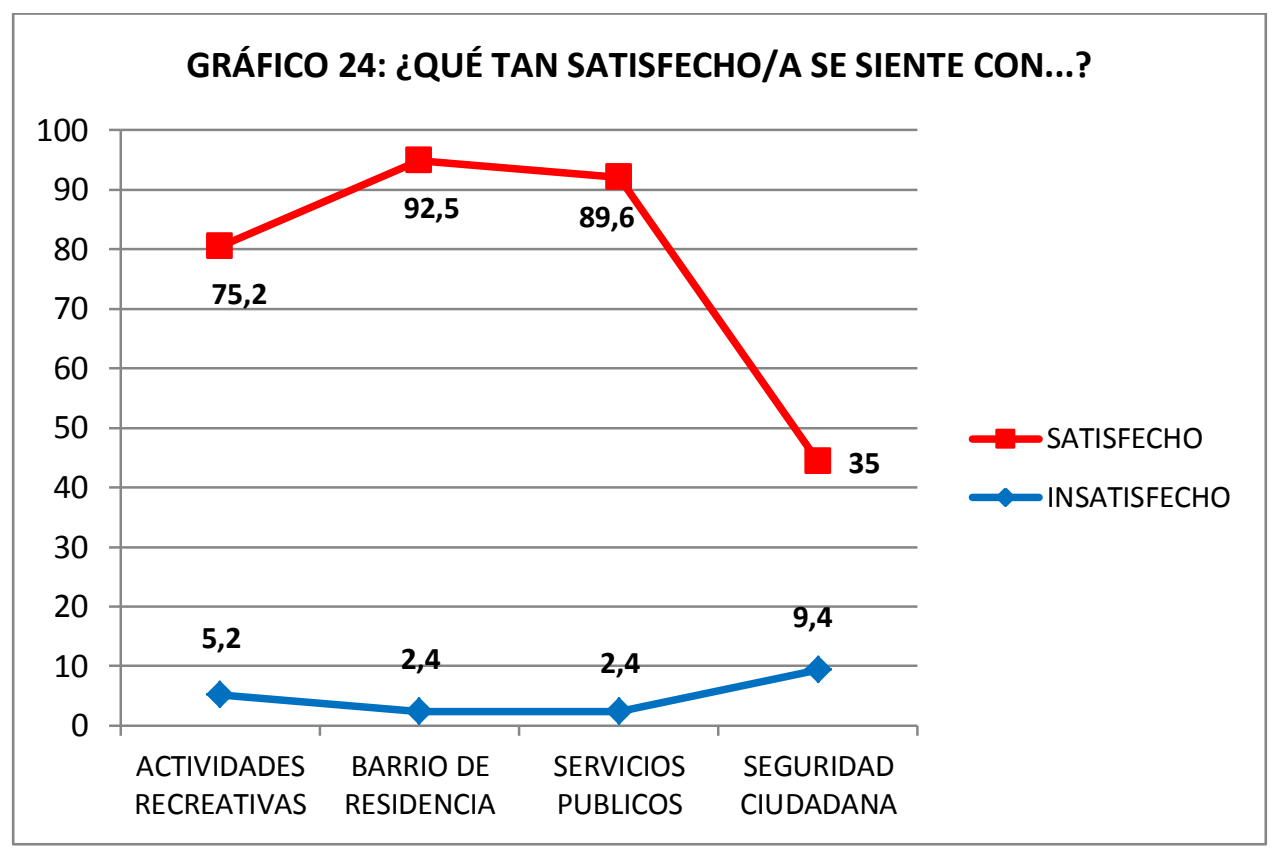




\section{MODULO 7: INDIVIDUO}

Hoy por hoy se dice que vivimos en una sociedad individualista, lo cual implica suponer que el individuo tiene preeminencia por sobre el colectivo social. Entendiendo que el valor de la libertad es uno de los más intrínsecos y fundamentales del ser humano, la exacerbación del individuo y la realización de su libertad trascienden todos los planos de su existencia, de manera tal que la autorrealización individual es un fin en sí mismo y, por cierto, el entorno social empuja al individuo a que alcance su autorrealización y felicidad. De esta manera, si bien es cierto la felicidad es apropiada individualmente, el contexto sociocultural influye en la construcción de marcos de sentido que son socializados a los individuos, esto es, internalizados a través de un proceso de construcción simbólica respecto de aquellos aspectos culturalmente deseables por la sociedad. De esta manera se constituyen cánones o estándares ideales de alcanzar, transformándose en imperativos socioculturales que es deseable lograr para conseguir la anhelada felicidad, especialmente a través de la búsqueda de placer inmediato, aunque sea efímero.

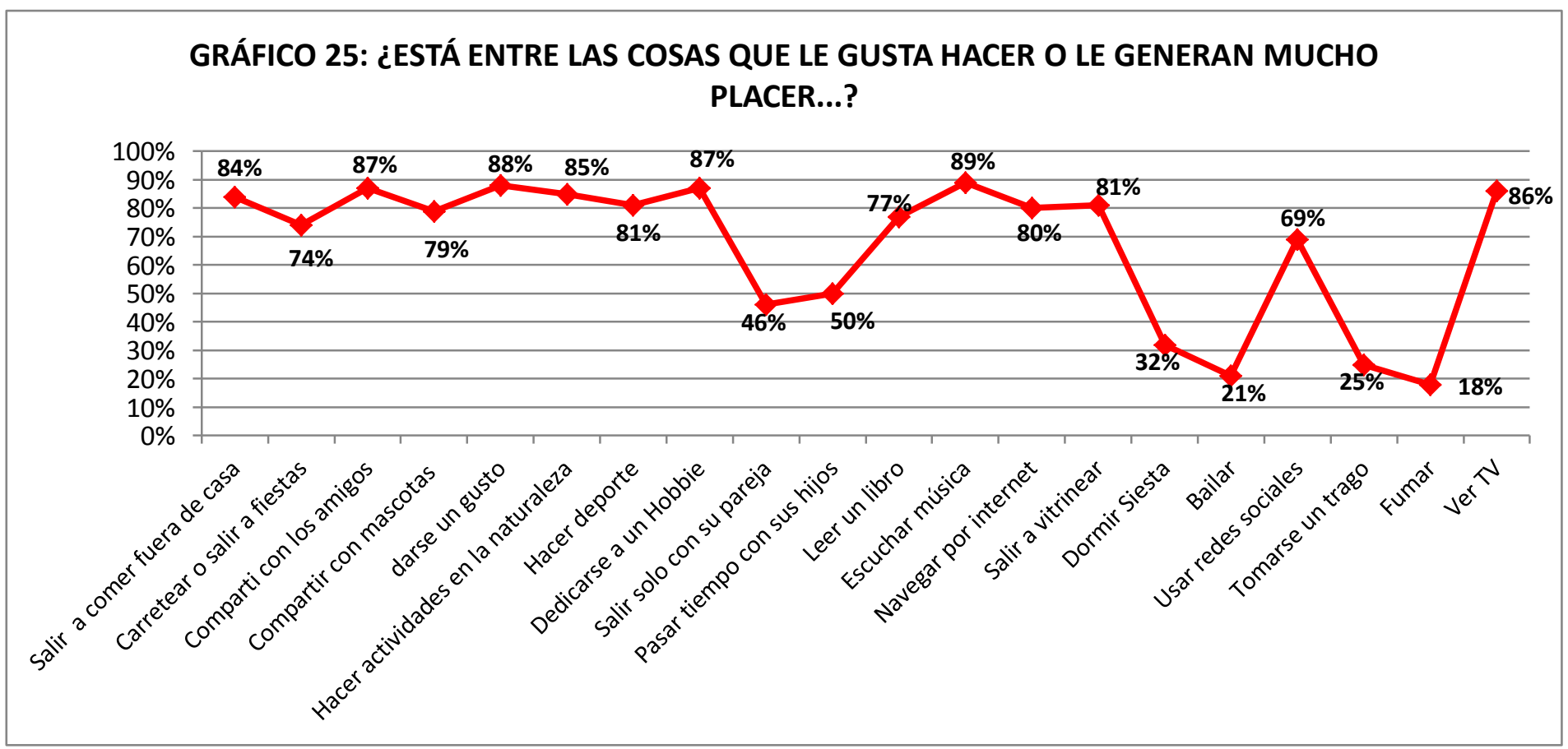

En virtud de lo comentado, es posible agrupar las actividades placenteras más destacadas por los talquinos en torno a las actividades físicas tales como "hacer actividades en la naturaleza", "hacer deporte" o "dedicarse a un hobbie", actividades de ocio tales como "Ver la TV", no obstante llama la atención que "salir solo con su pareja" o "pasar tiempo con sus hijos" sean dos actividades familiares que no concitan una fuerte adhesión. 


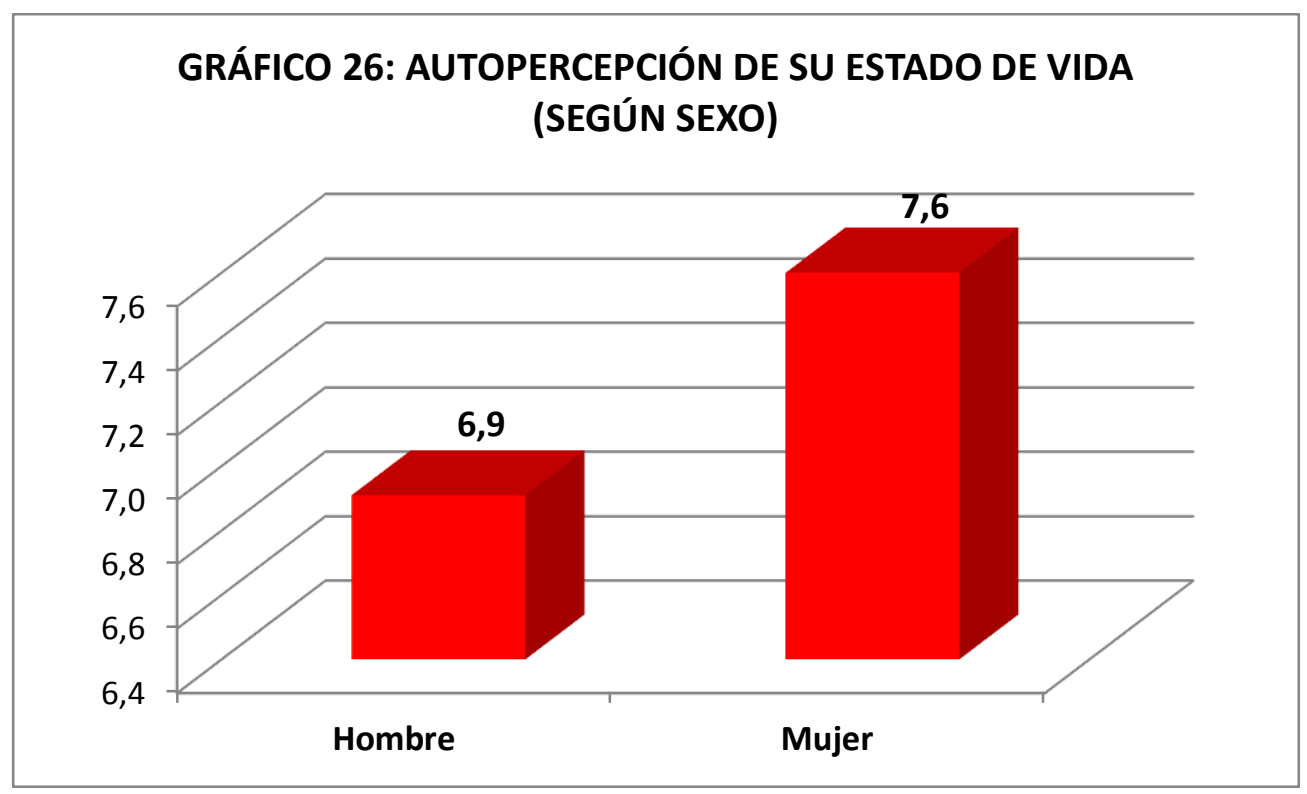

En una escala de 0 a 10 donde 0 significa la "peor vida posible" y 10 la "mejor vida posible", tenemos a los hombres quienes obtuvieron 6,9 puntos promedio, mientras que las mujeres obtuvieron 7,6 puntos promedio, de tal manera que las mujeres evalúan de manera más positiva su vida actual que los hombres.

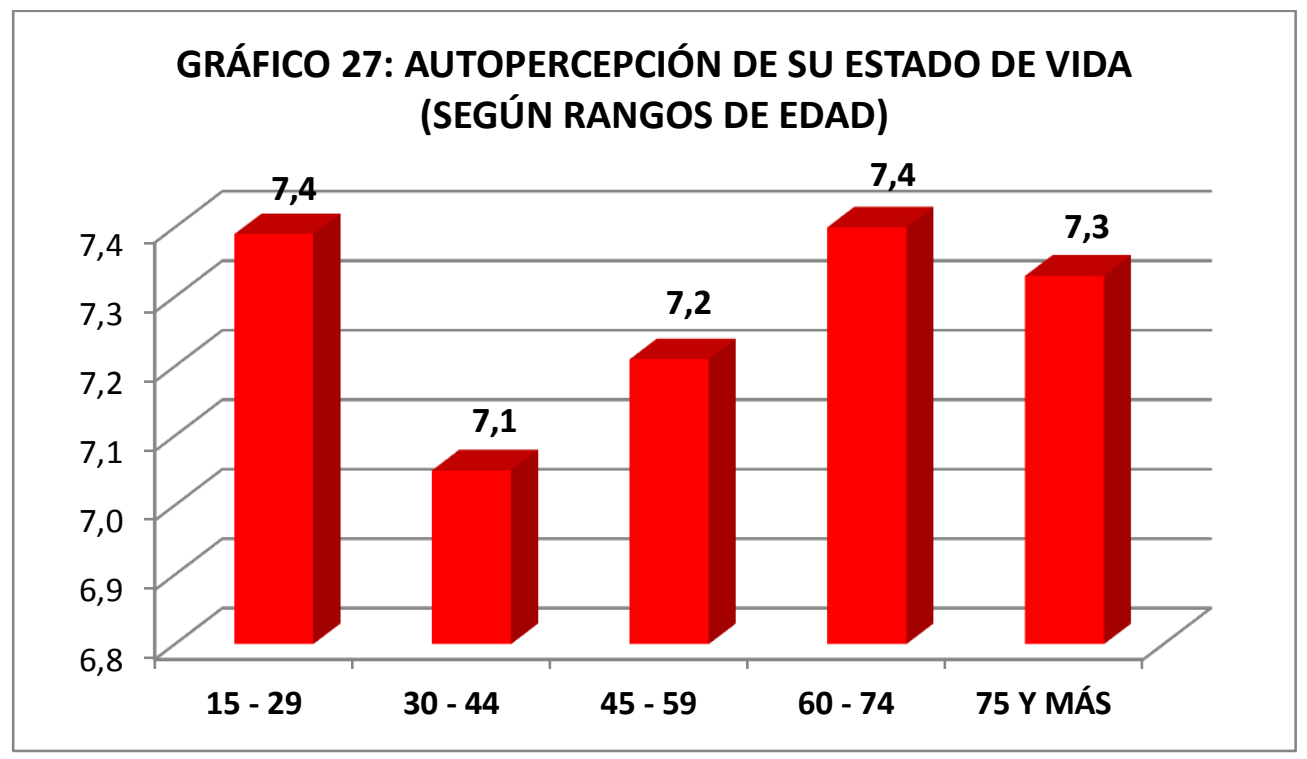

Llama la atención que el tramo 30 a 44 años sea aquel que presenta el índice de autopercepción de su estado de vida más bajo. Una explicación posible, intentando conectarla también con el gráfico anterior ( $\left.n^{\circ} 26\right)$, es que en este segmento etario las personas deben consolidar su futuro profesional y económico y el de sus familias, por lo tanto esta etapa se caracteriza de mucho trabajo, postergando las relaciones afectivas y familiares con el fin de lograr la anhelada consolidación que permita pavimentar un futuro próspero. Es probable que esta definición concuerde 
mayoritariamente con personas de sexo masculino, y por este motivo pudiera ser más baja la autoevaluación de su estado de vida en los hombres.

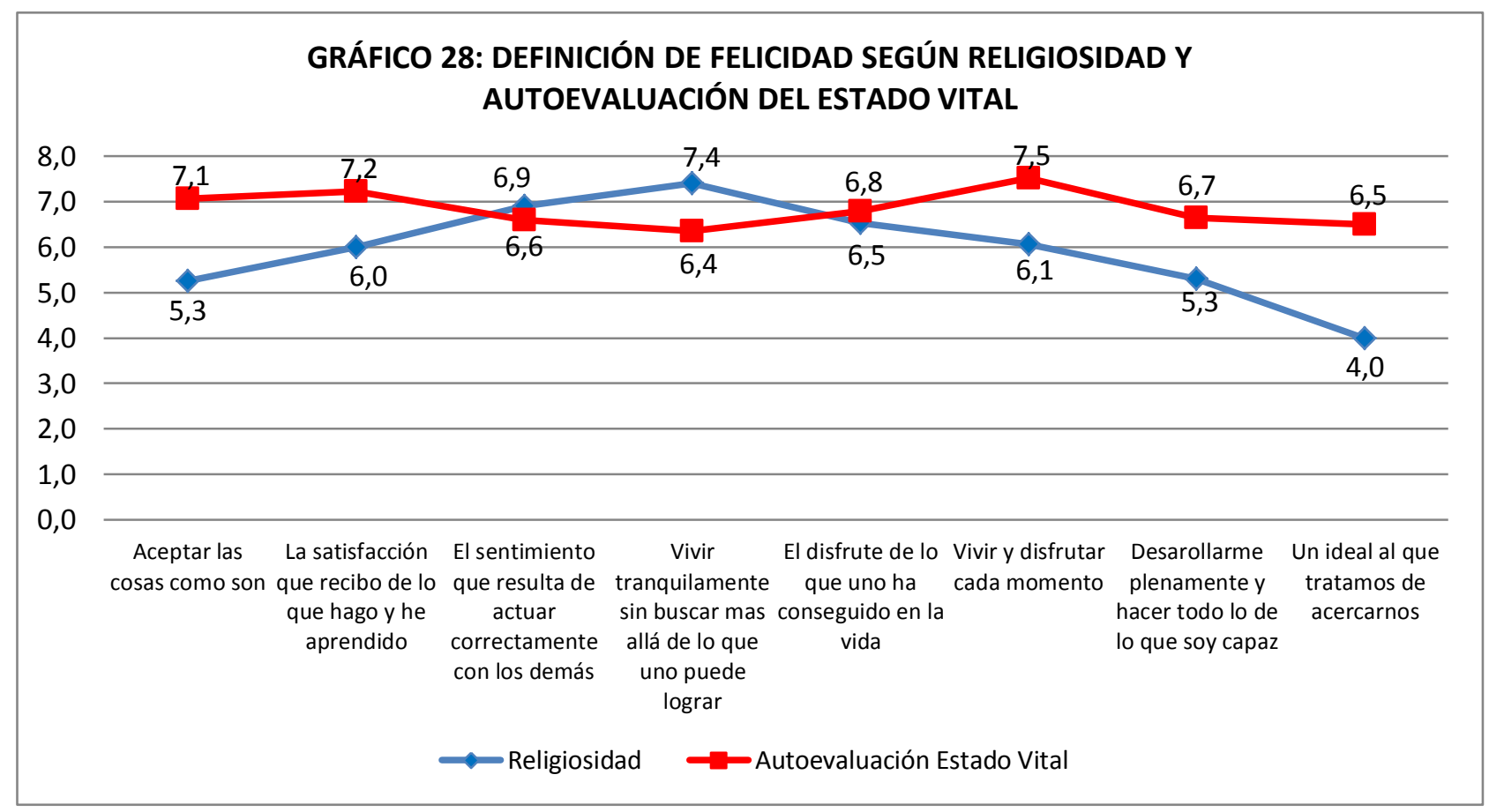

Este último gráfico refleja la definición de felicidad que más representa a los talquinos, controlando dicha apreciación según la religiosidad (de 0 "nada religioso" a 10 "muy religioso") y la Autoevaluación el Estado Vital (AEV), como ya explicamos en el gráfico 26. En síntesis, el mayor promedio de religiosidad (7,4 puntos) coincide con la definición de felicidad "vivir tranquilamente sin buscar más allá de lo que uno puede lograr", por lo tanto representa una concepción conformista de la felicidad, "conformarse con lo que a uno le tocó". Por otro lado, el promedio mayor de $\operatorname{AEV}$ (7,5 puntos) coincide con la definición de felicidad "vivir y disfrutar cada momento", por lo tanto representa una noción altamente dinámica del concepto felicidad y por lo tanto impredecible y efímera.

\section{CONSTRUYENDO UN MODELO DE CALIDAD DE VIDA DESDE EL ENFOQUE DEL BIENESTAR SUBJETIVO}

Después de revisar los siete módulos relativos a la conceptualización de la calidad de vida, entendemos que esta está compuesta por una dimensión de bienestar 
objetivo y por otra dimensión de bienestar subjetivo. El bienestar objetivo se define desde el acceso a bienes y servicios que permitan satisfacer necesidades materiales de los seres humanos. Complementariamente, el bienestar subjetivo se entiende como la satisfacción que experimentamos las personas respecto de nuestra propia vida, es decir, es una apreciación que hace el sujeto respecto de los diferentes ámbitos de su vida. A su vez, este bienestar subjetivo puede ser individual, vale decir, el bienestar experimentado por un sujeto determinado respecto de sí mismo, como también respecto de la sociedad, o sea, la percepción de un sujeto respecto de su entorno social.

Ahora bien, desde esta óptica se entiende que el bienestar subjetivo es experimentado por los individuos en diferentes dominios de vida. Estos dominios de vida corresponden a los siete módulos revisados: salud, empleo, ingresos, familia, amistades, comunidad y personal. Esto equivale a señalar que el bienestar subjetivo se experimenta en cada uno de estos dominios de vida en los que los seres humanos actuamos e interactuamos en sociedad. Desde esta perspectiva, entonces, entendemos que la percepción de la calidad de vida se homologa con el bienestar subjetivo y desde allí, asumimos que este es posible de medir a partir del criterio en base a la construcción de indicadores de "satisfacción en dominios de vida". En cuanto al primer componente, SALUD, se entiende que la valoración personal de la propia salud es más importante que la valoración experta cuando se relaciona con el bienestar (Moyano y Ramos, 2007). Por cierto que el estado de salud objetivamente se va deteriorando con la edad, lo cual debiera corresponder con una percepción sobre la propia salud diferentes entre jóvenes, adultos y adultos mayores. Sin embargo dentro de cada grupo, el cuidado y la historia personal generarán diferentes valoraciones subjetivas de la propia salud. El segundo componente, INGRESOS, resulta generar correlaciones significativas con el bienestar en sectores sociales vulnerables, pero aparentemente en sectores acomodados la correlación de los ingresos con el bienestar tendería a ser mínima (Veenhoven, 1996). Esto sería así pues a un nivel de bajos ingresos las necesidades materiales son múltiples y, por tanto, el aumento de ingresos en aquellos sectores generaría un impacto significativo en el consumo que, a su vez, influiría en la percepción de bienestar subjetivo de los individuos, en cambio en sectores acomodados, el aumento de ingresos influiría significativamente en el bienestar dado que aquellas personas tienen sus necesidades materiales satisfechas. Un tercer componente, el EMPLEO, se correlaciona positivamente con el bienestar desde el punto de vista que aquellos trabajadores que manifiestan mayor satisfacción con su trabajo presentan mayor bienestar, a diferencia de aquellos que presentan bajos niveles de satisfacción con el empleo o quienes se encuentran desempleados (Moyano y Ramos, 2007). El cuatro componente, la FAMILIA, se constituye en una dimensión del bienestar fundamental, dado que es el seno de la familia el espacio social donde se generan las interrelaciones afectivas más significativas para los individuos: la contención 
emocional, el apoyo psicosocial y económico, la confianza, etc., sin intermediar motivaciones de carácter racional-instrumental. Por lo tanto, aquellos sujetos que tienen una elevada satisfacción con sus familias también van a reportar altos niveles de bienestar. El componente AMISTAD, caracterizado por el cúmulo de relaciones interpersonales que las personas tenemos con otros referentes significativos en términos de amistad, también se correlaciona con el bienestar. De este modo, se sugiere que aquellos que cuentan con amistades reportan un bienestar mayor que quienes no las tienen, aun cuando la cantidad de amistades no sea directamente proporcional con aumentos significativos en el bienestar. El componente COMUNIDAD, hace referencia al entorno próximo de residencia de los individuos y comprende la percepción de seguridad del barrio, el acceso a servicios, el sentido de pertenencia, la percepción sobre los vecinos $y$, por cierto, el paisajismo y disponibilidad de áreas verdes. De esta manera, aquellas personas que se manifiesten elevados niveles de satisfacción con su comunidad también manifestarán altos niveles de bienestar. Por último, el componente PERSONAL (o individuo) refleja la satisfacción que manifiestan los individuos consigo mismos, de tal manera que aquellos que se sientan más satisfechos también reportarán un mayor bienestar. La satisfacción personal, por cierto, se asocia con los logros alcanzados por los individuos en conformidad con sus propias expectativas y con las expectativas sociales que están definidas también culturalmente.

De esta manera, se comprende que el bienestar subjetivo es un componente de la calidad de vida y que, por lo tanto, variaciones en la percepción del bienestar subjetivo individual y con la sociedad genera también variaciones en la calidad de vida de los individuos. 


\section{SEGUNDA PARTE: ANÁLISIS FACTORIAL DE COMPONENTES PRINCIPALES}

El Análisis Factorial de Componentes Principales (AFCP), es una técnica multivariable de reducción de dimensiones, que tiene como objetivo conocer el patrón de agrupamiento que tiene un grupo de variables respectos de una cantidad de componentes o dimensiones subyacentes no observables directamente. Tales factores tienen la característica de ser homogéneos entre sí (alta correlación entre las variables que lo componen) y heterogéneos en relación a los otros (baja correlación). El sentido tras esta técnica es mantener la mayor cantidad de información original (varianza) utilizando el mínimo de dimensiones posibles, con lo cual se asegura la parsimonia del modelo. El AFCP puede ser exploratorio o confirmatorio. La primera referencia, hace alusión a la búsqueda de un patrón empírico de agrupamiento a partir de un conjunto de variables ingresadas al modelo, por lo cual se utiliza en etapas iniciales de una investigación, cuando no existe conocimiento en torno a las dimensiones que teóricamente podrían agruparse las variables. Por el otro lado, el AFCP confimatorio, reviste utilidad cuando se posee un modelo teórico de agrupamiento en torno a dimensiones claramente definidas. En nuestro caso, dado que operamos a partir de un modelo teórico-conceptual ya existente, las características que asume el uso de esta técnica se centran más específicamente en esta segunda acepción, pues queremos saber si las variables introducidas al modelo se agrupan en torno a las siete dimensiones de los dominios de vida.

\section{TABLA 1: KMO Y PRUEBA DE BARTLETT}

\begin{tabular}{|l|l|l|}
\hline \multicolumn{2}{|l|}{$\begin{array}{l}\text { Medida de adecuación muestral de Kaiser- } \\
\text { Meyer-Olkin. }\end{array}$} &, 649 \\
\hline \multirow{3}{*}{$\begin{array}{l}\text { Prueba de esfericidad } \\
\text { de Bartlett }\end{array}$} & $\begin{array}{l}\text { Chi-cuadrado } \\
\text { aproximado }\end{array}$ & $\begin{array}{l}481,50 \\
9\end{array}$ \\
\cline { 2 - 3 } & gl & 153 \\
\cline { 2 - 3 } & Sig. &, 000 \\
\hline
\end{tabular}

La Tabla 1, permite evidenciar que el modelo es estadísticamente significativo, pues el valor de significación ostenta un valor 0,000 el cual es inferior al valor $p$ de contraste $(0,005)$, lo cual quiere de decir que estamos frente a un modelo susceptible de ser analizado. 
TABLA 2: VARIANZA TOTAL EXPLICADA

\begin{tabular}{|c|c|c|c|c|c|c|c|c|c|}
\hline \multirow{2}{*}{$\begin{array}{l}\text { Compon } \\
\text { ente }\end{array}$} & \multicolumn{3}{|c|}{ Autovalores iniciales } & \multicolumn{3}{|c|}{ 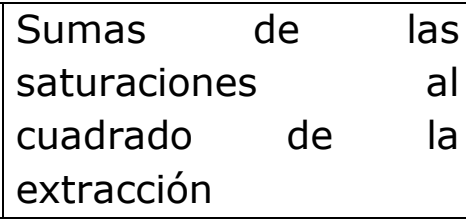 } & \multicolumn{3}{|c|}{$\begin{array}{l}\text { Suma de las } \\
\text { saturaciones al } \\
\text { cuadrado de la rotación }\end{array}$} \\
\hline & Total & $\begin{array}{l}\text { \% de } \\
\text { la } \\
\text { varia } \\
\text { nza }\end{array}$ & $\begin{array}{l}\% \\
\text { acumula } \\
\text { do }\end{array}$ & Total & $\begin{array}{l}\% \text { de } \\
\text { la } \\
\text { varian } \\
\text { za }\end{array}$ & $\begin{array}{l}\% \\
\text { acumul } \\
\text { ado }\end{array}$ & Total & $\begin{array}{l}\% \text { de } \\
\text { la } \\
\text { varian } \\
\text { za }\end{array}$ & $\begin{array}{l}\% \\
\text { acumul } \\
\text { ado }\end{array}$ \\
\hline 1 & 3,8 & 21,2 & 21,2 & 3,8 & 21,2 & 21,2 & 2,6 & 14,5 & 14,5 \\
\hline 2 & 2,2 & 12,2 & 33,5 & 2,2 & 12,2 & 33,5 & 2,4 & 13,5 & 28,0 \\
\hline 3 & 1,7 & 9,2 & 42,6 & 1,7 & 9,2 & 42,6 & 1,8 & 10,2 & 38,1 \\
\hline 4 & 1,4 & 8,0 & 50,6 & 1,4 & 8,0 & 50,6 & 1,7 & 9,4 & 47,6 \\
\hline 5 & 1,3 & 7,5 & 58,1 & 1,3 & 7,5 & 58,1 & 1,6 & 9,0 & 56,5 \\
\hline 6 & 1,3 & 7,2 & 65,3 & 1,3 & 7,2 & 65,3 & 1,6 & 8,7 & 65,3 \\
\hline 7 & 0,9 & 5,0 & 70,2 & & & & & & \\
\hline 8 & 0,8 & 4,3 & 74,5 & & & & & & \\
\hline 9 & 0,7 & 4,1 & 78,6 & & & & & & \\
\hline 10 & 0,7 & 3,7 & 82,3 & & & & & & \\
\hline 11 & 0,6 & 3,2 & 85,5 & & & & & & \\
\hline 12 & 0,5 & 3,0 & 88,5 & & & & & & \\
\hline 13 & 0,5 & 2,7 & 91,2 & & & & & & \\
\hline 14 & 0,4 & 2,3 & 93,5 & & & & & & \\
\hline 15 & 0,4 & 2,0 & 95,4 & & & & & & \\
\hline 16 & 0,3 & 1,9 & 97,3 & & & & & & \\
\hline
\end{tabular}




\begin{tabular}{|l|l|l|l|l|l|l|l|l|l|}
\hline 17 & 0,3 & 1,7 & 99,0 & & & & & & \\
\hline 18 & 0,2 & 1,0 & 100,0 & & & & & & \\
\hline
\end{tabular}

Método de extracción: Análisis de Componentes principales.

La Tabla 2 refleja que el modelo inicial se compone de 18 variables que fueron agrupadas en 6 dimensiones o componentes, los cuales en su conjunto mantienen el $65,3 \%$ de la varianza original. El primer factor conserva el $21,2 \%$ de la varianza, mientras que el segundo el $12,2 \%$, el tercero el $9,2 \%$, el cuarto el $8 \%$, y los componentes quinto y sextos conservan poco más del $7 \%$ de la varianza original cada uno. 
TABLA 3: MATRIZ DE COMPONENTES ROTADOS(a)

\section{ITEMS}

COMPONENTES

¿Qué tan satisfecho/a se encuentra con el empleo que tiene, o la actividad (Domestica) que realiza?

¿Qué tan satisfecho/a se encuentra con el horario y las responsabilidades de su empleo?

\begin{tabular}{l|l|l|l|l|l|}
$\mathbf{1}$ & $\mathbf{2}$ & $\mathbf{3}$ & $\mathbf{4}$ & $\mathbf{5}$ & $\mathbf{6}$ \\
\hline
\end{tabular}

¿Qué tan satisfecho/a se encuentra con la relación con sus colegas de trabajo?

¿Qué tan satisfecho/a se encuentra con la relación con su jefe?

¿Qué tan satisfecho se encuentra con la situación económica de su hogar?

¿Qué tan satisfecho se encuentra con las condiciones de su vivienda?

¿Qué tan satisfecho se encuentra con las cosas que puede comprar?

¿Qué tan satisfecho se encuentra con la cantidad de dinero que ahorra?

¿Qué tan satisfecho se encuentra con la capacidad de enfrentar problemas financieros?

¿Qué tan satisfecho/a se encuentra Ud. con la relación con su pareja?

¿Qué tan satisfecho/a se encuentra con la relación con sus hijos?

¿Qué tan satisfecho/a se encuentra con la relación con sus padres?

¿Qué tan satisfecho/a se encuentra con la relación con el resto de su familia?

¿Qué tan satisfecho/a se encuentra con la relación con sus amigos?

¿Qué tan satisfecho/a se encuentra con la relación con sus vecinos?

¿Qué tan satisfecho/a se encuentra con la disponibilidad de espacio para sus actividades recreativas en la comunidad

¿Qué tan satisfecho/a se encuentra con el barrio/sector donde vive?

¿Qué tan satisfecho/a se encuentra con los servicios públicos en el lugar donde vive? (recolección de basura, transporte, alumbrado, calles etc.)

\begin{tabular}{l|l|l|l|l|l|}
0,1 & 0,7 & 0,1 & 0,1 & 0,4 & 0,0 \\
\hline
\end{tabular}

\begin{tabular}{l|l|l|l|l|l|}
0,0 & 0,7 & 0,2 & 0,1 & 0,2 & 0,0 \\
\hline 0,2 & 0,8 & 0,0 & 0,0 & 0,0 & 0,1 \\
\hline
\end{tabular}

\begin{tabular}{l|l|l|l|l|l|l|}
0,2 & 0,8 & 0,0 & 0,0 & 0,0 & 0,1 \\
\hline 0,0 & 0,7 & 0,1 & $-0,1$ & 0,1 & 0,1 \\
\hline
\end{tabular}

\begin{tabular}{l|l|l|l|l|l|}
0,0 & 0,7 & 0,1 & $-0,1$ & $-0,1$ & 0,1 \\
\hline
\end{tabular}

\begin{tabular}{|l|l|l|l|l|l|}
0,7 & 0,1 & 0,0 & 0,1 & 0,0 & 0,0 \\
\hline
\end{tabular}

\begin{tabular}{|l|l|l|l|l|l|l|}
0,6 & 0,1 & 0,0 & 0,1 & 0,0 & 0,3 \\
\hline
\end{tabular}

\begin{tabular}{|l|l|l|l|l|l|l|}
0,7 & 0,2 & 0,1 & $-0,1$ & $-0,1$ & 0,2 \\
\hline
\end{tabular}

\begin{tabular}{|l|l|l|l|l|l|}
0,8 & 0,0 & 0,1 & $-0,1$ & 0,1 & 0,0 \\
\hline
\end{tabular}

\begin{tabular}{|l|l|l|l|l|l|}
0,8 & 0,1 & 0,2 & $-0,1$ & 0,2 & 0,1 \\
\hline
\end{tabular}

\begin{tabular}{|l|l|l|l|l|l|l|}
0,2 & 0,0 & 0,0 & 0,0 & 0,8 & 0,0 \\
\hline
\end{tabular}

\begin{tabular}{|l|l|l|l|l|l|}
0,0 & 0,2 & 0,1 & 0,0 & 0,7 & 0,1 \\
\hline
\end{tabular}

\begin{tabular}{|l|l|l|l|l|l|}
0,1 & 0,2 & 0,1 & 0,1 & 0,1 & 0,8 \\
\hline
\end{tabular}

Método de extracción: Análisis de componentes principales.

Método de rotación: Normalización Varimax con Kaiser. 
a. La rotación ha convergido en 6 iteraciones.

La tabla anterior, grafica los componentes rotados y permite crear el patrón de agrupamiento de las variables en torno a las seis dimensiones revisadas, de tal manera que respecto del modelo original, se ha perdido una dimensión. 
Como lo señalamos, la técnica del Análisis Factorial de Componentes Principales (AFCP) permite confirmar si los ítems elaborados en el instrumento cuantitativo generan mediciones que se agrupan en torno a los siete factores originalmente definidos según un criterio teórico como constitutivos del bienestar subjetivo. Una primera observación de la Tabla 1 muestra la prueba de esfericidad de Bartlett, la cual indica que el nivel de significación asociado a la prueba $(0,000)$ es menor que 0,05 por tal razón podemos sostener que las variables ingresadas al modelo son pertinentes para realizar este análisis. La Tabla 2 de varianza total explicada, indica que las 18 variables ingresadas al modelo se agrupan en torno a seis factores o componentes, los que en conjunto explican el $65,3 \%$ de la información original contenida en las variables (varianza). En definitiva, esta técnica permite evaluar los factores que emergen de la agrupación, eliminando del modelo aquellos ítems que no se agruparon con claridad en torno a algún factor o bien que distorsionaban su interpretación. De esta manera, el modelo definitivo queda como sigue:

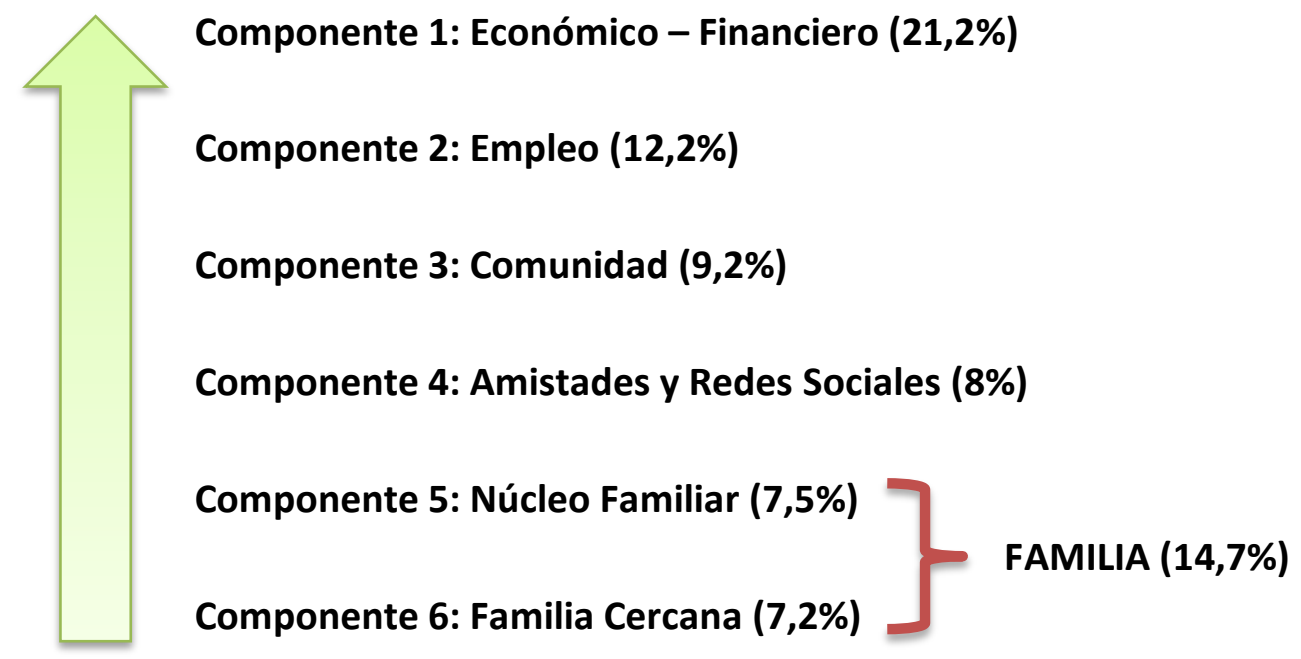

Finalmente, la Tabla 3 nos permite visualizar el criterio de agrupación de las variables del modelo en torno a los seis componentes generados, en la cual se aprecia, en orden de importancia, que el componente 1 está compuesto por cinco variables, el componente 2 por cuatro variables, el componente 3 por tres variables, el componente 4 por dos variables, el componente 5 por dos variables y el componente 6 por dos variables.

Como resultado, lo anterior nos lleva a concluir que la percepción de bienestar subjetivo para los talquinos y talquinas está fuertemente constituida en torno a: la tranquilidad económica, la satisfacción laboral, la satisfacción por el entorno residencial y por el sentido de construcción las relaciones familiares, compuestas por la familia nuclear (pareja e hijos) y la familia cercana (padres, hermanos y otros) y de relaciones de amistad. El núcleo afectivo, por lo tanto, 
es un componente fundamental que emerge con fuerza y que incluso desplaza la dimensión "individual" o "personal", en la que el bienestar está fuertemente determinado por la autorrealización del individuo a través de la búsqueda de placer inmediato. El componente "comunidad", referido especialmente a lo que hemos denominado "comunidad inmediata" en este estudio, se configura como el espacio de construcción de sentido y de experiencias significativas en torno al barrio o sector de residencia. El componente "económico-financiero" deviene en el más importante de los seis y, por cierto, refiere a la satisfacción de los talquinos con sus ingresos y con su capacidad de gasto para satisfacer sus necesidades. Finalmente el componente "empleo" relativo a la satisfacción con la labor productiva en sí misma y a las relaciones humanas en el espacio laboral, se convierte en el segundo componente en importancia y releva el valor que tiene para las personas desarrollar una actividad productiva que sea significativa en un contexto de desenvolvimiento grato de las relaciones interpersonales en el contexto de trabajo.

\section{EFECTOS DEL TERREMOTO EN LA CALIDAD DE VIDA DE LOS TALQUINOS}

A tres años del megaterremoto que azotó la zona centro sur de nuestro país, y muy particularmente nuestra región, quisimos averiguar cuáles son los efectos aun perdurables percibidos por los talquinos. Basta un recorrido por el centro de la ciudad de Talca y por su casco histórico para advertir, como una cicatriz indeleble, algunos sitios eriazos donde una vez hubo inmuebles. Fachadas de edificios en pie vacías en su interior, vestigios de casas, patios de luz y un montón de historias familiares que se derrumbaron aquel fatídico día. Pero más allá del panorama visible, con el que hemos aprendido a convivir cotidianamente, existen consecuencias intangibles en la población que son evidentes. No cabe ninguna duda que la magnitud de este evento puso a prueba todos los sistemas de emergencia y el abastecimiento de los servicios básicos, pero también nuestra capacidad de organizarnos solidariamente para intentar volver a la normalidad lo más rápido posible, en cuyo proceso cumplieron una labor notable los medios de comunicación locales.

En referencia con las mencionadas consecuencias psicosociales, económicas, materiales, etc. ocasionadas por el terremoto del 27/F en la población talquina, podemos advertir que las tres consecuencias principales, según muestra la gráfica 29 , tiene que ver con problemas para dormir $(23,1 \%)$, temor a los temblores $(19,4 \%)$ y retraso en el inicio escolar $(17,4 \%)$. Probablemente en términos generales, las consecuencias menores de este fenómeno natural fueron de tipo económico (pérdida de la fuente laboral), pero las mayores se asocian a consecuencias psicosociales de carácter emocional (miedo, angustia, 
temor, problemas para dormir, estrés, etc.) y aquellas de tipo material (daño estructural a la vivienda y a los bienes personales).
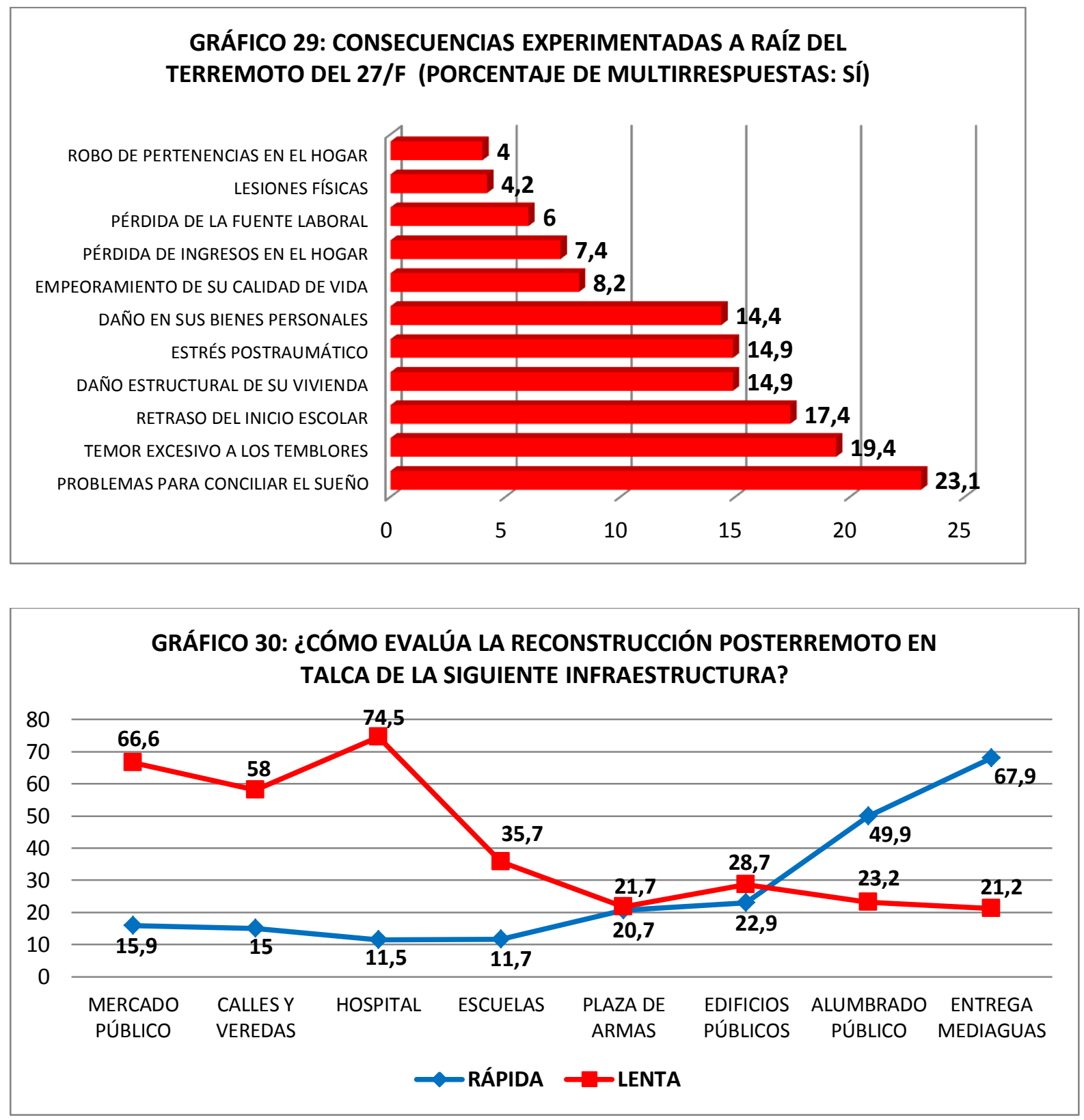

Ahora bien, a nivel de la evaluación de la ciudadanía respecto de la rapidez del proceso de reconstrucción de la infraestructura de la ciudad, en el gráfico se advierte claramente que el "Hospital" resulta ser la infraestructura que más se ha demorado en ser reconstruida (74,5\% percibe que ha sido lenta o muy lenta), seguida por el "Mercado" (66,6\%) y las "calles y veredas" (58\%), mientras que la infraestructura reconstruida con mayor rapidez según la percepción de la ciudadanía talquina ha sido la "entrega de mediaguas" 
(67,9\% percibe que ha sido rápida o muy rápida) y la reposición del alumbrado público $(49,9 \%)$.

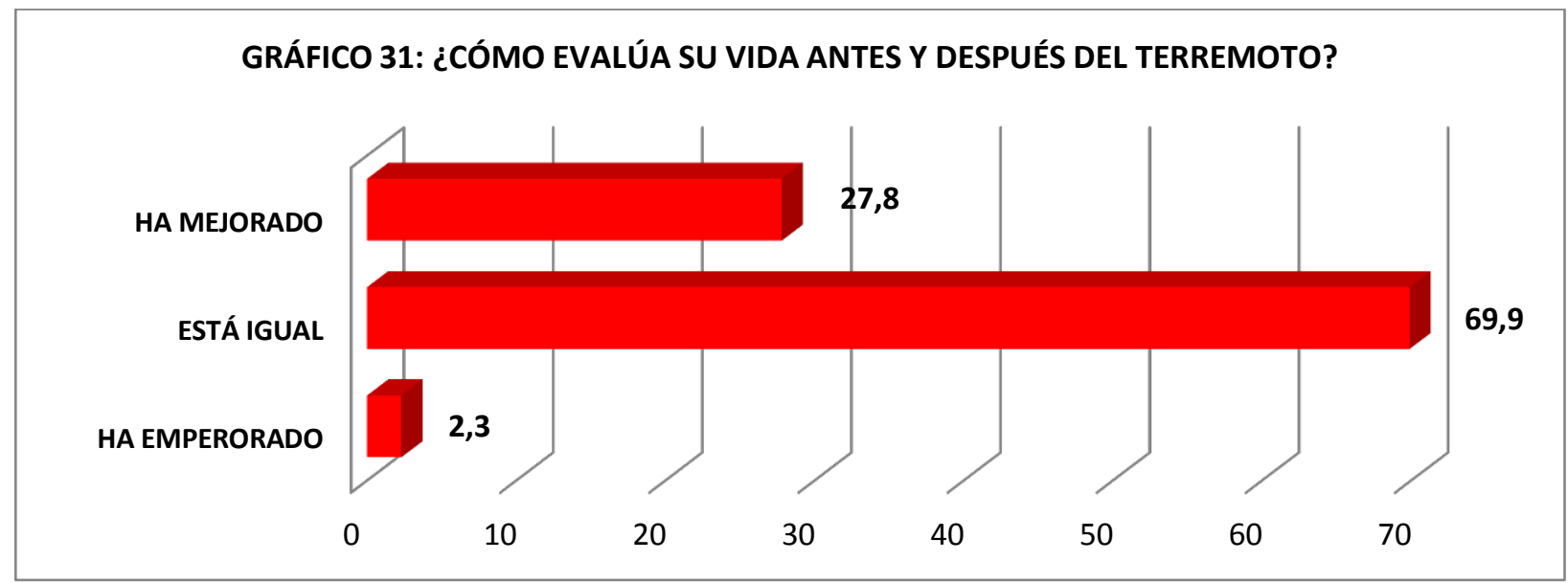

A nivel general se advierte que la ciudadanía percibe mayoritariamente que su vida sigue igual en comparación a como era antes del terremoto $(69,9 \%)$ lo cual indica que no hubo grandes consecuencias en el desenvolvimiento de la vida cotidiana de la mayoría de los talquinos.

TABLA 4: PERCEPCIÓN DE VIDA ACTUAL SEGÚN PERCEPCION DE LOS EFECTOS DEL TERREMOTO (27/F) EN SU VIDA

\begin{tabular}{|c|c|c|c|c|}
\hline \multirow[t]{2}{*}{$\left|\begin{array}{ll}\text { PERCEPCIÓN } \\
\text { DE } & \text { VIDA } \\
\text { ACTUAL } & \end{array}\right|$} & \multicolumn{3}{|c|}{ 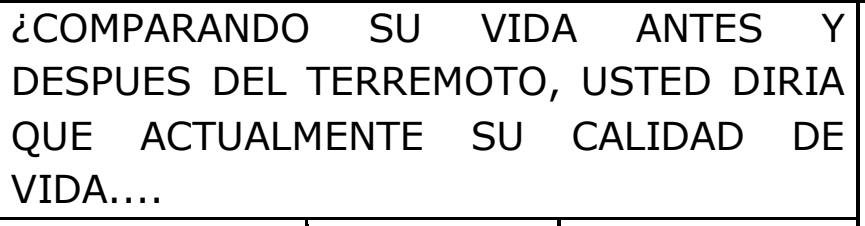 } & \multirow[b]{2}{*}{$\begin{array}{l}\text { TOT } \\
\text { AL }\end{array}$} \\
\hline & $\begin{array}{l}\text { HA } \\
\text { EMPEORADO }\end{array}$ & $\begin{array}{l}\text { ESTA } \\
\text { IGUAL }\end{array}$ & \begin{tabular}{|l} 
HA \\
MEJORADO
\end{tabular} & \\
\hline MUY MAL & & $3,6 \%$ & $1,8 \%$ & $\begin{array}{l}3,0 \\
\%\end{array}$ \\
\hline MAL & $33,3 \%$ & $13,4 \%$ & $15,5 \%$ & $\begin{array}{l}14,4 \\
\%\end{array}$ \\
\hline REGULAR & $55,6 \%$ & $16,6 \%$ & $17,3 \%$ & $\begin{array}{l}17,7 \\
\%\end{array}$ \\
\hline BIEN & $11,1 \%$ & $27,1 \%$ & $26,4 \%$ & $\begin{array}{l}26,5 \\
\%\end{array}$ \\
\hline MUY BIEN & & $39,4 \%$ & $39,1 \%$ & $\begin{array}{l}38,4 \\
\%\end{array}$ \\
\hline
\end{tabular}




\section{TABLA 4: PERCEPCIÓN DE VIDA ACTUAL SEGÚN PERCEPCION DE LOS EFECTOS DEL TERREMOTO (27/F) EN SU VIDA}

\begin{tabular}{|c|c|c|c|c|}
\hline \multirow[t]{2}{*}{$\begin{array}{ll}\text { PERCEPCIÓN } \\
\text { DE } & \text { VIDA } \\
\text { ACTUAL } & \end{array}$} & \multicolumn{3}{|c|}{$\begin{array}{lcccc}\text { ¿COMPARANDO } & \text { SU } & \text { VIDA } & \text { ANTES } & \text { Y } \\
\text { DESPUES DEL TERREMOTO, USTED DIRIA } \\
\text { QUE ACTUALMENTE } & \text { SU } & \text { CALIDAD } & \text { DE } \\
\text { VIDA.... } & & & \\
\end{array}$} & \multirow[b]{2}{*}{$\begin{array}{l}\text { TOT } \\
\text { AL }\end{array}$} \\
\hline & $\begin{array}{l}\text { HA } \\
\text { EMPEORADO }\end{array}$ & \begin{tabular}{|l} 
ESTA \\
IGUAL
\end{tabular} & \begin{tabular}{|l} 
HA \\
MEJORADO
\end{tabular} & \\
\hline MUY MAL & & $3,6 \%$ & $1,8 \%$ & \begin{tabular}{|l}
3,0 \\
$\%$
\end{tabular} \\
\hline MAL & $33,3 \%$ & $13,4 \%$ & $15,5 \%$ & $\begin{array}{l}14,4 \\
\%\end{array}$ \\
\hline REGULAR & $55,6 \%$ & $16,6 \%$ & $17,3 \%$ & $\begin{array}{l}17,7 \\
\%\end{array}$ \\
\hline BIEN & $11,1 \%$ & $27,1 \%$ & $26,4 \%$ & $\begin{array}{l}26,5 \\
\%\end{array}$ \\
\hline MUY BIEN & & $39,4 \%$ & $39,1 \%$ & $\begin{array}{l}38,4 \\
\%\end{array}$ \\
\hline Total & $100,0 \%$ & $100,0 \%$ & $100,0 \%$ & $\begin{array}{l}100, \\
0 \%\end{array}$ \\
\hline
\end{tabular}

Esta última tabla resume el cruce de la variable "efectos del terremoto en la vida de los talquinos" con la "percepción de la vida actual". En esta tabla de contingencia se advierte que la percepción de la vida actual asume valores más positivos en la medida que se percibe que la calidad de vida después del terremoto ha mejorado en comparación a como era antes del terremoto. En este sentido, cabe destacar que esta fue una de las ciudades capitales más afectadas por aquel fenómeno natural, de manera tal que la relativamente pronta recuperación del terremoto por parte de la ciudadanía también se cuantifica en la percepción de la ciudadanía sobre su bienestar y no solamente se visualiza a partir de aspectos materialmente visibles, sino que se palpa en el buen estado de ánimo de la población.

\section{CONCLUSIONES}

La realización de este estudio significó introducirnos en el mundo de las subjetividades de los talquinos en relación con la percepción respecto su bienestar subjetivo. De esta manera, se midieron siete dimensiones o componentes en términos de dominios de vida, que son aquellos espacios sociales en los que los individuos actúan e interactúan desempeñando diferentes roles. Dichos componentes son: Salud, Empleo, Ingresos, Familia, 
Amistades, Comunidad y Persona. Algunos de estos componentes tienen que ver con la autopercepción del sujeto sobre sí mismo, como es el caso, por ejemplo, de la salud, vale decir, el individuo valora su propio estado de salud "cuán satisfecho se siente con ella", más allá de los diagnósticos médicos: una persona puede tener una enfermedad crónica como, por ejemplo, hipertensión, pero como cada individuo sobrelleva su vida y su enfermedad y en definitiva "el cómo se sienta" va a depender de otros factores. No tendrán la misma percepción de bienestar, entonces, dos adultos mayores que sean hipertensos y diabéticos, uno con un contacto familiar cercano y periódico y el otro sin contacto familiar. Ahora bien, en rigor los talquinos evalúan positivamente su estado de "salud", dado que el $80 \%$ percibe que su estado de salud es bueno o muy bueno, y una cifra similar está "satisfecho" o "muy satisfecho" con su estado de salud. Donde sí se advierte una mala evaluación es en la calidad de los recintos de salud ( $25 \%$ cree que la calidad es mala o muy mala) y en la disponibilidad de médicos especialistas ( $35 \%$ cree que la disponibilidad es mala o muy mala). Con relación al "empleo", en promedio los talquinos trabajan 0,6 horas semanales más que las talquinas, aproximadamente el $70 \%$ se encuentra afiliado a un sistema de pensiones pero sólo el $60 \%$ cotiza regularmente. En rigor, los talquinos tienen una alta percepción de su empleo, valorando, eso sí, más las relaciones interpersonales en el trabajo que las tareas y responsabilidades propias del empleo. Con relación a los "ingresos", el ingreso familiar mensual promedio de los talquinos es de $\$ 528.105$ (considerando salarios, subsidios, pensiones y otros tipos de ingresos), el promedio de miembros por familia es de 3,6 personas, por lo tanto, el ingreso per cápita promedio es de $\$ 148.762$. El nivel de satisfacción promedio de los talquinos con sus ingresos es medio ( 3,6 puntos) y la satisfacción con su capacidad de ahorro es bajo (2,9 puntos) de un máximo de 5 puntos posibles. Lo anterior implica un nivel alto de endeudamiento y una baja capacidad para enfrentar problemas financieros. Respecto de la "familia", los talquinos declaran una alta satisfacción con sus relaciones familiares (padres, pareja, hijos y resto de la familia), como asimismo se señala que se realizan acciones en familia de manera habitual, tales como: "salir juntos en familia", "conversar temas familiares", "salir a comer juntos" y "ver TV juntos", de manera tal que se declara cierta conformidad con sus relaciones con los otros miembros de sus familias. Respecto de las "amistades", para los talquinos es importante contar con amigos (un $70 \%$ opina que es más importante tener amigos que dinero), pero la densidad de las relaciones de amistad disminuye conforme se avanza en el ciclo vital. A pesar de lo anterior, el 56\% de los talquinos declara estar insatisfecho o muy insatisfecho con sus amistades, lo cual implica que a pesar que se reconoce la importancia de la amistad, no se evalúa positivamente las amistades que se tiene, lo cual se complementa con el hecho de que un $15 \%$ de los encuestados se siente solo. Luego, la 
evaluación de la comunidad resulta ser positiva, siendo los aspectos mejor evaluaos el entorno residencial y la accesibilidad/disponibilidad de servicios, y el aspecto peor evaluado es la seguridad ciudadana en sus lugares de residencia. Finalmente, respecto del componente "personal", la evidencia empírica indica que los talquinos tienen una percepción bastante positiva de sus vidas, con un promedio de 7,3 puntos (en un rango de 0 a 10), distinguiéndose diferencias de género a favor de las mujeres, lo cual puede ser explicado, introduciendo la variable rango etario, producto de que el tramo de edad de 30 a 59 años es aquél en que se produce una leve baja en la percepción positiva de la vida actual, lo cual coincidiría con que aquello corresponde a una mayor proporción de hombres y aquello tendría sus razones en el hecho de que se trataría de personas en plena edad productiva, en un contexto laboral que hoy por hoy deja pocos espacios para desarrollar plenamente la vida familiar producto de la alta cantidad de horas que se trabaja y de lo competitiva que es esta actividad.

Estas subjetividades son las que marcan la diferencia y, por lo tanto, el pulso hacia dónde deben enfocarse las políticas sociales actuales, pues se entiende que no basta solo con el hecho de preocuparse por la cobertura, la eficiencia y la eficacia de los programas sociales, sino que también de las subjetividades de los receptores de las políticas con el propósito de mejorar no sólo su calidad de vida material, sino que la autopercepción que tienen de sí mismos y de su entorno.

Finalmente, este estudio nos permitió adentrarnos en la dimensión subjetiva de las consecuencias sociales del terremoto del pasado 27/F de 2010. A casi tres años de aquel fenómeno de magnitudes históricas aún persisten algunas consecuencias en la población que, por cierto, involucran aspectos materiales de infraestructura, pérdida de bienes personales y costos económicos asociados a la reconstrucción, pero también, y de manera más solapada, persisten problemas psicoemocionales y psicosociales entre los que destacan el "temor exacerbado a los temblores" y la "dificultad de conciliar el sueño". De todas maneras, aparentemente el terremoto no afectó de manera significativa de los talquinos, pues la mayoría se declara estar igual a como vivía antes del terremoto $(69,9 \%)$ y tan sólo un $2,3 \%$ señala que su vida ha empeorado después del terremoto en comparación a como vivía antes. Finalmente, respecto de la evaluación que hace la ciudadanía en torno a la velocidad del proceso de reconstrucción, se puede advertir que al menos el $50 \%$ de la infraestructura evaluada en este estudio, la ciudadanía percibe un ritmo de reconstrucción lento o muy lento y sólo el $25 \%$ de la reconstrucción de la infraestructura es evaluada de manera favorable (rápida o muy rápida). 
Finalmente, intentando responder a la pregunta inicialmente formulada, la evidencia empírica sugiere que tanto las expectativas personales como sociales de los talquinos son mediatizadas por el componente familiar. Muchos de los logros individuales, que en ciudades grandes, donde existe un mayor énfasis competitivo, se orientan a la autosatisfacción personal a través de la exacerbación del consumo, al parecer en el contexto sociocultural talquino dicha autorrealización pasa por el bienestar familiar.

\section{REFERENCIAS BIBLIOGRÁFICAS}

CUMMINS, Robert (1996) Quality of Life Measurement: Generic and Psychometric Issues, "10th World Congress, International Association for the Scientific Study of Intellectual Disability"

DE RAMÓN, Armando (1995). Un progreso interrumpido: el caso de Talca durante la segunda mitad del siglo XIX [versión electrónica]. Eure, 21 (62), 33-47.

INFORME DE DESARROLLO HUMANO (2012) "Bienestar Subjetivo: el desafío de repensar el desarrollo", Programa de las Naciones Unidas para el Desarrollo (PNUD), Santiago.

MARTUCCELLI, Danilo (2007) "Cambio de Rumbo. La Sociedad a escala del individuo", LOM Ediciones, Santiago.

MOYANO, Emilio y RAMOS, Nadia (2007) "Bienestar Subjetivo: midiendo satisfacción vital, felicidad y salud en población chilena en la Región del Maule", en Calidad de Vida y Psicología en el Bicentenario de Chile (2010), Ediciones Universidad de Talca.

ROJAS, Mariano (2011a) "Más allá del ingreso: progreso y bienestar subjetivo" en "La medición del progreso y del bienestar: Propuestas desde América latina", Foro Consultivo Científico y Tecnológico, México D.F.

ROJAS, Mariano (2011b) "El Bienestar Subjetivo: Su contribución a la apreciación y la consecución del Progreso y el Bienestar Humano", Revista Internacional de Estadística y Geografía, Volumen 2, №1, México.

SÁNCHEZ, Raúl (2012) "Entre el partido del Maule... y Talca, París y Londres", Presentación del Coloquio sobre desarrollo y emprendimiento en el Maule, realizado en el mes de Junio de 2012 en la Universidad Autónoma de Chile, sede Talca (material inédito) 
VEENHOVEN, Ruut (1996) "Developments in Satisfaction Research". Social Indicators Research N037.

\section{BASES DE DATOS REVISADAS}

ENCUESTA DE CARACTERIZACIÓN SOCIOECONOMICA NACIONAL 2011 (CASEN)

CENTRO DE ESTUDIOS PÚBLICOS (CEP) "AUDITORÍA A LA DEMOCRACIA" (NOVIEMBRE 2012).

\section{POLÍTICAS PÚBLICAS PARA IMPULSAR LA INNOVACIÓN SOCIO- TÉCNICA EN PEQUEÑAS LOCALIDADES}

\section{Resumen}

Este trabajo, producto de la investigación realizada para la Universidad de La Punta, San Luis, "Observatorio del uso social de tecnologías de información y comunicación en localidades" (2011 - 2012), analiza el proceso desarrollado por el programa San Luis Digital (SLD) en la Provincia de San Luis, Argentina, para promover la apropiación social de las tecnologías de información y comunicación (TIC) en localidades de menos de 2.500 habitantes. El artículo examina las estrategias utilizadas por el gobierno provincial para superar las resistencias culturales y difundir la apropiación progresiva de las TIC y sus diversas aplicaciones y programas en la vida cotidiana (actividades sociales, culturales y económicas). Se analizan la percepción e impacto de los programas de SLD, y los fenómenos de "contagio" de adopción del uso de Internet y computadoras. La investigación, cuali-cuantitativa, se focaliza sobre ciertos perfiles predeterminados de habitantes en cuatro localidades de la Provincia separadas geográficamente: El Trapiche, Papagayos, Villa del Carmen y Nueva Galia.

\section{Abstract}

This paper is based on the research "Observatory of the social use of information and communication technologies (ICT) in small localities" (20112012). It analyzes the process developed by the San Luis Digital Program in San Luis Province, Argentina, to promote social appropriation of ICT in towns wit a population under 2.500 inhabitants. The article examines the strategies used by the provincial government in order to overcome cultural resistance 